\title{
OBSERVATIONAL AND THEORETICAL STUDIES OF THE DYNAMICS OF MANTLE PLUME-MID-OCEAN RIDGE INTERACTION
}

\author{
G. Ito \\ Department of Geology and \\ Geophysics, School of Ocean \\ and Earth Science and Technology, \\ University of Hawaii, \\ Honolulu, Hawaii, USA
}

\author{
J. Lin \\ Department of Geology and \\ Geophysics, \\ Woods Hole Oceanographic Institution, \\ Woods Hole, Massachusetts, USA
}

\author{
D. Graham \\ College of Oceanic and \\ Atmospheric Sciences, \\ Oregon State University, \\ Corvallis, Oregon, USA
}

Received 24 July 2002; revised 16 May 2003; accepted 5 August 2003; published 20 November 2003.

[1] Hot spot-mid-ocean ridge interactions cause many of the largest structural and chemical anomalies in Earth's ocean basins. Correlated geophysical and geochemical anomalies are widely explained by mantle plumes that deliver hot and compositionally distinct material toward and along mid-ocean ridges. Compositional anomalies are seen in trace element and isotope ratios, while elevated mantle temperatures are suggested by anomalously thick crust, low-density mantle, low mantle seismic velocities, and elevated degrees and pressures of melting. Several geodynamic laboratory and modeling studies predict that the width over which plumes expand along the ridge axis increases with plume flux and excess buoyancy and decreases with plate spreading rate, plume viscosity, and plume-ridge separation. Key aspects of the theoretical predictions are supported by observations at several prominent hot spotridge systems. Still, many basic aspects of plume-ridge interaction remain enigmatic. Outstanding problems pertain to whether plumes flow toward and along midocean ridges in narrow pipe-like channels or as broad expanding gravity currents, the origin of geochemical mixing trends observed along ridges, and how mantle plumes alter the geometry of the mid-ocean ridge plate boundary, as well as the origin of other ridge axis anomalies not obviously related to mantle plumes. INDEX TERMS: 8121 Tectonophysics: Dynamics, convection currents and mantle plumes; 3035 Marine Geology and Geophysics: Midocean ridge processes; 1025 Geochemistry: Composition of the mantle; 8120 Tectonophysics: Dynamics of lithosphere and mantle-general; 3210 Mathematical Geophysics: Modeling; KEYWORDS: hot spot, mid-ocean ridge, mantle plume, mantle convection, MORB, OIB

Citation: Ito, G., J. Lin, and D. Graham, Observational and theoretical studies of the dynamics of mantle plume-mid-ocean ridge interaction, Rev. Geophys., 41(4), 1017, doi:10.1029/2002RG000117, 2003.

\section{INTRODUCTION}

[2] Hot spots and mid-ocean ridges are two major surface manifestations of mantle upwelling and magma generation on Earth. (Italicized terms are defined in the glossary, after the main text.) Separation of oceanic plates at mid-ocean ridges draws mantle upward and induces partial melting. Hot spots, on the other hand, are often thought to result from buoyant upwelling of anomalously hot convection plumes arising from the deep mantle [Morgan, 1971]. Of the 30-50 identified present-day hot spots, at least 21 appear to be interacting with mid-ocean ridges (Figure 1). These hot spotridge interactions induce physical and chemical anomalies along $15-20 \%$ of the length of the global mid-ocean ridge system.
[3] A global map of residual oceanic topography (topographic effects of sedimentation and lithospheric cooling removed, see Figure 1 caption for details) reveals regions of seafloor that are anomalously shallow over areas of $10^{6} \mathrm{~km}^{2}$ (Figure 1). Many of these regions are bathymetric swells associated with hot spots. Hot spot swells encompassing mid-ocean ridges are locations of hot spot-ridge interaction (labeled in Figure 1). In many cases, hot spot-ridge interaction has probably continued for many tens of millions of years as indicated by swells that extend well away from mid-ocean ridges onto old seafloor. Some hot spot-ridge interactions construct giant volcanic edifices in the form of oceanic plateaus such as those currently extending from Iceland in the North Atlantic and the Cocos Ridge in the equatorial Pacific. In fact, many of the largest volcanic features on 


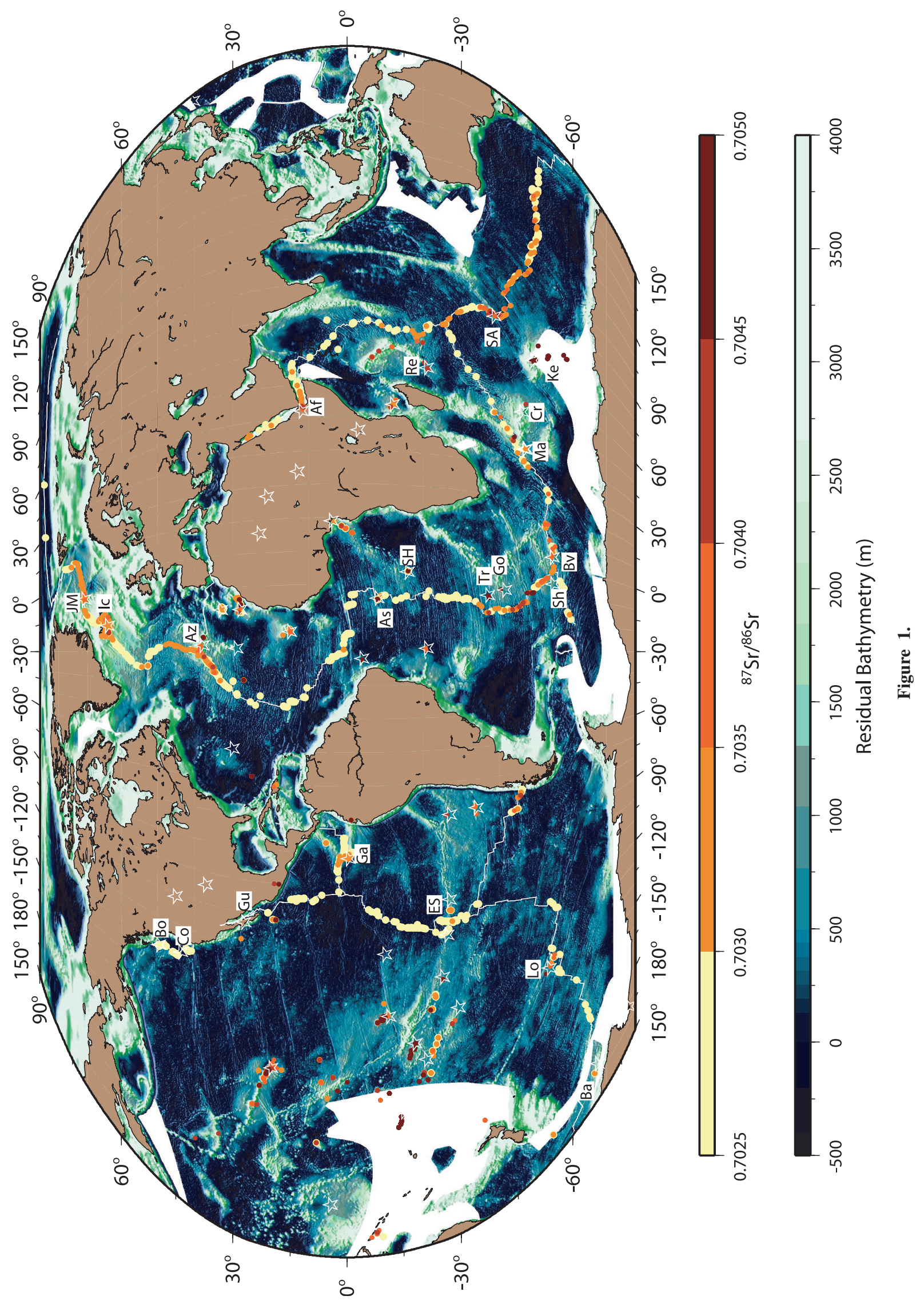




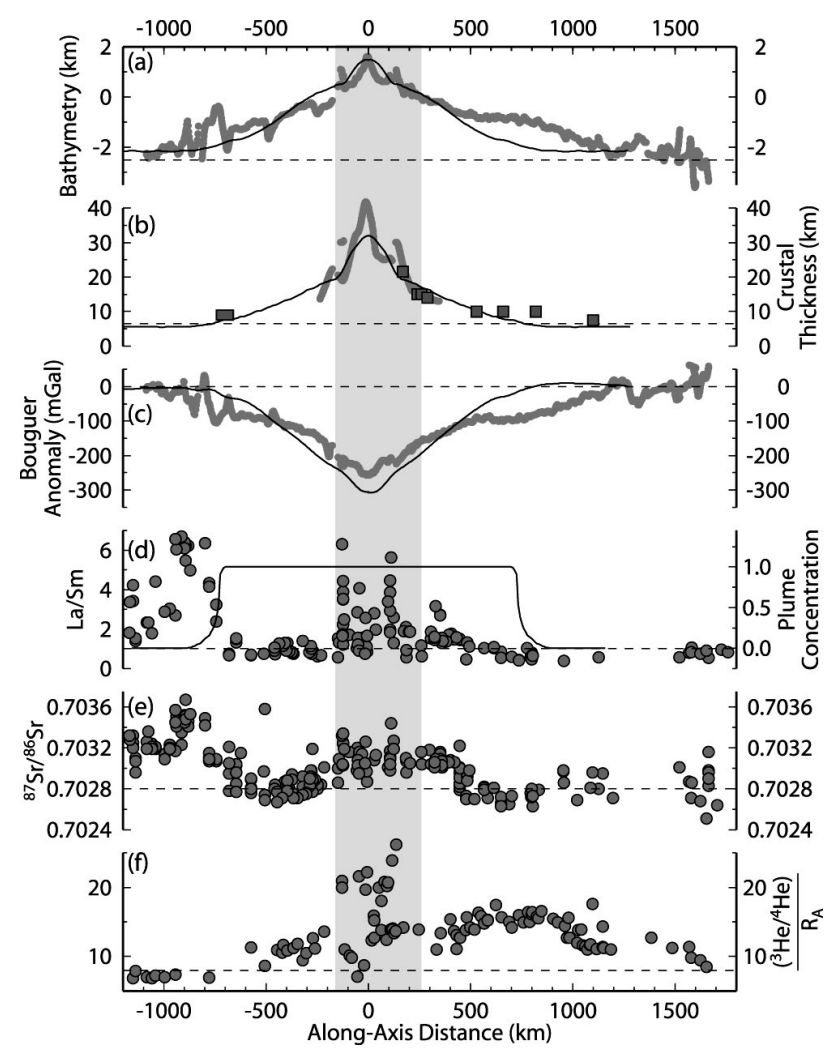

Figure 2. (a) Bathymetry (shaded curve) along the MidAtlantic Ridge (MAR) centered on Iceland [Ito et al., 1996]. (b) Seismically constrained crustal thicknesses on Iceland (shaded curve) [Darbyshire et al., 2000] and along the MAR (boxes compiled by M. Mochizuki and B. Brandsdóttir (personal communication, 2002)) [Bunch and Kennett, 1980; Bjarnason et al., 1993; Smallwood et al., 1995; Kodaira et al., 1997; Navin et al., 1998; Weir et al., 2001]. (c) Bouguer gravity on Iceland [Eysteinsson and Gunnarsson, 1995] and along the MAR [Ito et al., 1999]. Thin curves in Figures 2a-2c are predictions of three-dimensional (3-D) geodynamic models [Ito et al., 1999]. (d) La/Sm and (e) ${ }^{87} \mathrm{Sr} /{ }^{86} \mathrm{Sr}$ [Hart et al., 1973; Schilling, 1973; Schilling et al., 1983, 1999; Hemond et al., 1993] and (f) ${ }^{3} \mathrm{He} /{ }^{4} \mathrm{He}$ (normalized by atmospheric ratio $R_{A}$ [see Graham, 2002, and references therein]) variations along the MAR. Curve in Figure $2 d$ is proportion of plume material contributing to melts predicted by 3-D geodynamic model of Ito et al. [1999]. In Figures 2a-2f, large shaded band marks extent of subaerial Iceland, and thin horizontal lines mark reference values of the above quantities.
Earth such as the Kerguelen Plateau in the southern Indian Ocean and Ontong Java Plateau in the western Pacific may be relicts of extreme hot spot activity at or near ancient mid-ocean ridges [Coffin and Gahagan, 1995]. Hot spot-ridge interaction is thus an important process in shaping the Earth's surface at present day and in the geologic past.

[4] Basalts associated with hot spot volcanism generally display elevated concentrations of incompatible elements and radiogenic isotope concentrations that indicate these enrichments are long-lived ( $>10^{8}$ years). In contrast, mid-ocean ridge basalts (MORBs) display low concentrations of many of these same incompatible elements, with radiogenic isotopes ratios consistent with long-term depletion. For example, Figure 2 shows a compilation of ${ }^{87} \mathrm{Sr} /{ }^{86} \mathrm{Sr}$ ratios measured in basalt samples taken along mid-ocean ridges and ocean islands. (The isotope ${ }^{87} \mathrm{Rb}$ decays to ${ }^{87} \mathrm{Sr}$, and ${ }^{86} \mathrm{Sr}$ is the stable isotope. $\mathrm{Rb}$ is more incompatible than $\mathrm{Sr}$.) Many sections of ridges have compositions transitional between common MORBs and ocean island basalts (OIBs). These radiogenic isotope enrichments correlate remarkably well with increases in mid-ocean ridge bathymetry (Figures 1 and 2), suggesting a close link between physical characteristics (e.g., density and temperature) and composition of the underlying mantle.

[5] It was these correlations that J.-G. Schilling and coworkers began to recognize in the early 1970s [Schilling, 1971, 1973; Hart et al., 1973], which, combined with the mantle plume concept [Morgan, 1971, 1972] and theories of mantle flow [Vogt, 1971, 1972; Vogt and Johnson, 1972], led to the interpretation of hot spotridge interactions as interactions between mantle plumes and oceanic spreading centers. The basic hypothesis is that hot mantle plumes, compositionally distinct from the upper mantle, rise to the base of the lithosphere and feed material toward and along mid-ocean ridges. This concept has provided a framework for understanding hot spot-ridge systems and has stimulated a wealth of studies over the past 30 years.

[6] This manuscript reviews some of the key processes of plume-ridge interaction. With this focus we do not seek a comprehensive review of all plume-ridge systems studied, rather we highlight typical examples. We begin

Figure 1. Residual bathymetry of the ocean basins and ${ }^{87} \mathrm{Sr} /{ }^{86} \mathrm{Sr}$ along the mid-ocean ridges and ocean islands. Positive is anomalously shallow, and negative is anomalously deep. Original bathymetry is a global grid derived from shipboard soundings and satellite altimetry [Smith and Sandwell, 1997]. We corrected for the thickness and loading effects of sediments using the sediment thickness and density grids from Laske and Masters [1997]. The seafloor age map of Müller et al. [1993a] (unconstrained in white areas) and the model of Stein and Stein [1992] were then used to remove the normal deepening of the seafloor with age because of lithospheric cooling. Circles mark rock sample locations and are colored according to ${ }^{87} \mathrm{Sr} /{ }^{86} \mathrm{Sr}$ value (from http://georoc.mpch-mainz.gwdg.de/Entry.html and http://petdb.ldeo.columbia.edu/petdb/databases). Hot spots are shown by stars, and hot spots influencing mid-ocean ridges are labeled: Af, Afar; As, Ascension; Az, Azores; Ba, Balleny; Bo, Bowie; Bv, Bouvet; Co, Cobb; Cr, Crozet; ES, Easter/Sala y Gomez; Ga, Galapagos; Go, Gough; Gu, Guadalupe; Ic, Iceland; JM, Jan Mayen; Ke, Kerguelen; Lo, Louisville; Ma, Marion; Re, Reunion; SA, St. Paul-Amsterdam; Sh, Shona; SH, St. Helena; and Tr, Tristan de Cunha. 
with a summary of some basic observations that have shaped our understanding of plume-ridge interaction, followed by a synthesis of the numerical modeling and laboratory studies that elucidate the physical processes. Last, we highlight several outstanding problems. We intend this manuscript to reflect the earth science community's increasing emphasis on integrating geophysical methods, geochemical observations, and geodynamic models to gain quantitative understanding of the dynamics of plume-ridge interaction.

\section{EVIDENCE FOR "MANTLE PLUME"-RIDGE INTERACTION}

\subsection{Geochemical Tracers of Different Mantle Sources}

[7] Trace element and isotope ratios in magmas largely reflect the ratios in their mantle source and are therefore tracers of the chemical evolution of mantle. One difficulty in using elemental ratios as indicators of the mantle source is that they can also be affected by the melting process that generated the sampled rock. Isotope ratios, on the other hand, more directly reflect ratios in the source because isotopes of the same element have similar chemical behavior and do not fractionate during magma formation and migration. Furthermore, isotopes (e.g., ${ }^{87} \mathrm{Sr}$ ) with long parent half-lives $\left({ }^{87} \mathrm{Rb}\right.$ half-life is $\left.\sim 49 \mathrm{Gyr}\right)$ do not grow significantly into the melt on the timescale of magma genesis, and therefore the isotope ratio of the rock $\left({ }^{87} \mathrm{Sr} /{ }^{86} \mathrm{Sr}\right)$ is a robust measure of that in the mantle source as well as the time-integrated parent-daughter elemental ratio $(\mathrm{Rb} / \mathrm{Sr})$

[8] A number of processes over geologic time change trace element and thus isotopic ratios in the mantle from which hot spot and mid-ocean ridge basalts are derived. For example, melting extracts highly incompatible elements from mantle peridotite and concentrates these elements in crustal material. Consequently, peridotite that has experienced melting evolves to a more "depleted" trace element or isotopic composition compared to a more "undepleted" or "primitive" peridotite that has experienced little chemical fractionation. Sediments, crust, and lithosphere can be reincorporated or recycled back into the mantle by subduction or other tectonic processes and can introduce strong heterogeneities when they are again extracted at mid-ocean ridges and hot spots. A variety of isotopic systems (e.g., Rb-Sr, $\mathrm{Sm}-\mathrm{Nd}, \mathrm{U}-\mathrm{Pb}$, Lu-Hf, Re-Os, and U-Th-He) have been used to trace these different materials, though the association of compositional end-member "components" [e.g., White, 1985; Zindler and Hart, 1986] with distinct lithologies is complex and nonunique.

[9] Among the most powerful tracers of primitive material are the noble gases. Helium has been extensively studied, and neon is becoming more so. Essentially all of Earth's ${ }^{3} \mathrm{He}$ is primordial (i.e., it was trapped during Earth formation), while ${ }^{4} \mathrm{He}$ is created in the mantle by radioactive decay of $U$ and Th. Helium is highly incompatible and volatile, so it is efficiently extracted from the solid earth by melting and magmatism. Furthermore, because He experiences gravitational escape from the atmosphere with an atmospheric residence time of only $1-10 \mathrm{Myr}$, it is not recycled by subduction, so there is a net loss of ${ }^{3} \mathrm{He}$ from the mantle. The ${ }^{3} \mathrm{He} /{ }^{4} \mathrm{He}$ ratio measured in an oceanic basalt is an indicator of the time-integrated ratio of ${ }^{3} \mathrm{He} /(\mathrm{U}+\mathrm{Th})$ in its mantle source and is therefore a tracer of the primitive nature of this source [e.g., Kurz et al., 1982; Lupton, 1983]. With regard to neon, ${ }^{20} \mathrm{Ne}$ and ${ }^{22} \mathrm{Ne}$ are primordial isotopes, while ${ }^{21} \mathrm{Ne}$ is produced in small amounts by nucleogenic processes in the mantle. The ${ }^{21} \mathrm{Ne} /{ }^{22} \mathrm{Ne}$ and ${ }^{20} \mathrm{Ne} /{ }^{22} \mathrm{Ne}$ ratios may also be used to trace the primitive nature of mantle sources. For example, compared to mid-ocean ridge basalts, OIBs with elevated (more primitive) ${ }^{3} \mathrm{He} /{ }^{4} \mathrm{He}$ ratios have lower (more primitive) ${ }^{21} \mathrm{Ne} /$ ${ }^{22} \mathrm{Ne}$ ratios [Honda et al., 1993; Moreira et al., 2001]. Figure 2 shows that elevated ${ }^{3} \mathrm{He} /{ }^{4} \mathrm{He}$ ratios on Iceland decrease to typical MORB values along the Mid-Atlantic Ridge (MAR) $\sim 500 \mathrm{~km}$ north and $\sim 1700 \mathrm{~km}$ south of Iceland. The peak in ${ }^{3} \mathrm{He} /{ }^{4} \mathrm{He}$ over Iceland is situated near peaks in $\mathrm{La} / \mathrm{Sm}$ and ${ }^{87} \mathrm{Sr} /{ }^{86} \mathrm{Sr}$, but the wavelength of the $\mathrm{He}$ anomaly is much broader and similar in length to the bathymetric anomaly. The decoupling between $\mathrm{He}$ and other isotopes is not well understood, but it is an important clue to the mantle sources and melting processes involved [e.g., Schilling et al., 1999].

[10] The trace element and isotopic differences between MORBs and OIBs are usually interpreted as reflecting distinct mantle sources. The MORB source is depleted in incompatible elements, exhibits evidence for only minor proportions of recycled or primitive material [e.g., Hanan and Graham, 1996], displays higher values of ${ }^{21} \mathrm{Ne} /{ }^{22} \mathrm{Ne}$, and displays lower values of ${ }^{3} \mathrm{He} /{ }^{4} \mathrm{He}$, with a remarkably limited range (typically 7-9 times the atmospheric ratio $R_{A}$ ) [Kurz, 1991; Graham, 2002]. Collectively, these observations suggest a MORB mantle source that has experienced ancient melting and a minimal flux of recycled materials [e.g., White, 1985; Zindler and Hart, 1986]. In contrast, OIBs sample material that is more enriched in incompatible elements and represents a much larger range in isotope compositions, possibly reflecting the presence of subducted sediments [Armstrong, 1981; Weaver et al., 1986], subducted oceanic crust [Hofmann and White, 1982], subducted continental lithosphere [McKenzie and O'Nions, 1983], or variable combinations of all of these [Zindler and Hart, 1986]. In addition, the more primitive ${ }^{3} \mathrm{He} /{ }^{4} \mathrm{He}\left(>30 R_{A}\right)[\mathrm{Kurz}$, 1991; Graham, 2002], ${ }^{20} \mathrm{Ne} /{ }^{22} \mathrm{Ne}$, and ${ }^{21} \mathrm{Ne} /{ }^{22} \mathrm{Ne}$ ratios [Honda et al., 1993; Moreira et al., 2001] observed at ocean islands suggest that hot spots can sample primitive mantle that has experienced little ancient melting and degassing.

[11] Although still debated [Anderson, 1996; Foulger et al., 2001], the compositional differences between OIBs and MORBs provide geochemical support for the hy- 
pothesis of deep-seated mantle plumes. The upper manthe is an attractive reservoir for the MORB source because it can be isotopically depleted by mid-ocean ridge melting. The deep mantle is an attractive reservoir for the OIB source because it is spatially secluded from extensive mid-ocean ridge melting and degassing. The lower mantle may also be a storage zone of materials of ancient subduction [e.g., Hart et al., 1992; van der Hilst, 1997; Kellogg et al., 1999]. Kinematically, a mantle plume originating from a boundary layer in the deep mantle is an attractive explanation for the fixity of hot spots [Wilson, 1963; Morgan, 1971, 1972] or at least hot spot reference frames [Wessel and Kroenke, 1997; Norton, 2000] that are distinct from the migrating plates. Thus the general kinematic, physical, and chemical characteristics of hot spots provide a "unified plume theory" [Okal and Batiza, 1987], with some plumes rising beneath and interacting with mid-ocean ridges.

\subsection{Geophysical Evidence for Anomalously Thick Crust and Hot Mantle Beneath Hot Spot-Affected Ridges}

[12] Geophysical studies at the Iceland and Galapagos hot spot-ridge systems show compelling evidence for ridge interactions with hot mantle plumes. Iceland is a classic example of a ridge-centered plume. Here the Mid-Atlantic Ridge rises $\sim 4 \mathrm{~km}$ above normal ridge depths (Figure 2a) reaching an elevation of nearly $2 \mathrm{~km}$ at Grimsvötn volcano, the approximate center of the Iceland hot spot. The MAR remains anomalously shallow for $\sim 1000 \mathrm{~km}$ north and south of Iceland, making this hot spot swell the broadest on Earth. Coinciding with this topographic anomaly is a Bouguer gravity low (Figure 2c) [Eysteinsson and Gunnarsson, 1995; Ito et al., 1999]. From the outskirts of the along-axis swell, Bouguer gravity decreases toward Iceland reaching a minimum of approximately $-250 \mathrm{mGal}$ over Iceland's center. The topographic and gravity anomalies both indicate a broad region of anomalously low-density material beneath the MAR.

[13] Seismic studies indicate that a large portion of this density anomaly is thickened volcanic crust [e.g., Menke et al., 1996; Staples et al., 1997; Darbyshire et al., 1998]. Near Grimsvötn the crust is thickest at $\sim 40 \mathrm{~km}$ (Figure 2b) or 5-6 times the thickness of normal midocean ridge crust. North and south of this point, the crust thins rapidly to $<20 \mathrm{~km}$ near Iceland's coasts some $200 \mathrm{~km}$ away. The offshore crust thins more gradually, maintaining a thickness of $8-10 \mathrm{~km}$ for a distance of $\sim 500 \mathrm{~km}$ from Iceland. Darbyshire et al.'s [2000] seismic and gravity study determines that the crust accounts for a large portion but not all of the excess topography and low Bouguer gravity anomaly. They attribute the remaining contribution to anomalously low-density mantle. The inferred mantle density anomalies beneath Grimsvötn are large $\left(60-90 \mathrm{~kg} \mathrm{~m}^{-3}\right)$, and if caused by elevated temperatures alone, they would require mantle to be at least $450^{\circ}$ hotter than the mantle far from Iceland.

[14] Similar studies have been done along the Galapagos Spreading Center [Ito and Lin, 1995a; Canales et al., 2002]. Contrasting with Iceland, the Galapagos hot spot is off-axis, situated $\sim 200 \mathrm{~km}$ to the south of the spreading center. Approaching the hot spot along the Galapagos Spreading Center from the west, the hot spot swell shoals by $\sim 700 \mathrm{~m}$, and mantle Bouguer gravity (MBA) (which is derived from free-air gravity by subtracting the effects of the seafloor and crust-mantle interfaces, assuming crust of uniform density and thickness) decreases by $\sim 60 \mathrm{mGal}$ [Canales et al., 2002]. The seismic crustal thickness increases along the ridge toward the hot spot reaching a maximum excess of $2.4 \mathrm{~km}$ or $\sim 40 \%$ greater than normal crustal thicknesses far from the hot spot. Much like Iceland, the excess crust accounts for only a portion of the swell topography $(52 \%)$ and MBA $(60 \%)$, with the remaining portion of these anomalies attributed to relatively low density mantle nearest the hot spot. Canales et al. [2002] attribute this density anomaly to excess mantle temperatures $\left(\sim 30^{\circ} \mathrm{C}\right)$ as well as a compositional anomaly caused by elevated degrees of partial melting associated with the Galapagos hot spot.

[15] Recent efforts have been made to test the plume hypothesis by seismically imaging the mantle beneath hot spots [e.g., Zhang and Tanimoto, 1992; Wolfe et al., 1997; Shen et al., 1998; Allen et al., 1999; Bijwaard and Spakman, 1999; Foulger et al., 2001; Toomey et al., 2001; Zhao, 2001]. Beneath Iceland, there is evidence for a columnar-shaped region of low seismic wave speed in the upper mantle. Tomographic imaging [Wolfe et al., 1997; Allen et al., 2002], corroborated by receiver function studies [Shen et al., 1998], constrains the diameter of the plume to be relatively narrow $(\sim 100-300 \mathrm{~km})$ and the maximum excess temperature to be high $\left(\geq 150^{\circ} \mathrm{C}\right)$. Beneath the Galapagos hot spot, preliminary seismic tomography results reveal a structure in the mantle also consistent with a narrow, hot mantle plume [Toomey et al., 2001].

\subsection{Geochemical Evidence for Elevated Mantle Temperatures}

[16] Models of mantle melting have revealed a great deal of insight on the conditions needed to generate the excess crustal thickness as well as variations in major and trace element chemistry at hot spot-influenced midocean ridges. The earliest melting models considered pressure release partial melting of mantle as it rises beneath mid-ocean ridges. In these first-generation models, mantle flow was considered to be a passive response to plate spreading: The spreading plates drive a mantle corner flow with upwelling beneath the ridge axis and horizontal shear to each side of the ridge axis. McKenzie [1984] established a physical description of melting that related the thickness of crust to variations in mantle temperature. Shortly following, were studies that 
added predictions of major element [Klein and Langmuir, 1987; McKenzie and Bickle, 1988; Langmuir et al., 1992] and trace element chemistry [McKenzie and O'Nions, 1991; White et al., 1992, 1995].

[17] One outcome of such studies is evidence for excess mantle temperatures at hot spot-influenced ridges. Incompatible elements such as Na preferentially partition into melt; consequently, their concentration is high at low degrees of melting and decreases at higher degrees of melting with the dilution of more compatible elements. Such behavior is an attractive explanation for a global negative correlation between regional averages of crustal thickness and $\mathrm{Na}_{8}\left(\mathrm{Na}_{8}\right.$ is concentration after correcting for low-pressure crystallization, see Figure $3 \mathrm{a}$ and caption). Thin crust is explained by lower mantle temperatures and lower average degrees of melting and thus elevated $\mathrm{Na}_{8}$; whereas thicker crust, such as that generated near hot spots, is explained by higher mantle temperatures, greater average degrees of melting, and lower $\mathrm{Na}_{8}$ (Figure 3a). The melting model of Klein and Langmuir [1987] requires mantle temperature variations of $200^{\circ}-300^{\circ} \mathrm{C}$ to explain the total variations in crustal thickness and $\mathrm{Na}_{8}$ in Figure $3 \mathrm{a}$.

[18] Other elements such as Fe are more sensitive to the pressure or depth at which melting begins. An increase in $\mathrm{FeO}$ with depth of melting [Langmuir and Hanson, 1980] is supported by a negative correlation between regional averages of $\mathrm{Fe}_{8}$ and $\mathrm{Na}_{8}$ [Klein and Langmuir, 1987]. The proposed scenario is that anomalously hot mantle begins to melt deeper than normal mantle and has a relatively high Fe content. In addition, hot mantle will tend to melt to a greater degree and have a relatively low Na content. This negative correlation is preserved after correcting for different degrees of incompatible element enrichments in the mantle source [Shen and Forsyth, 1995] (Figure 3b). Shen and Forsyth's [1995] theoretical curves predict that the hot spot-influenced ridges start melting at the greatest depths or pressures. These pressures are also consistent with mantle temperature anomalies exceeding $100^{\circ} \mathrm{C}$. Finally, inversions of trace element concentrations [White et al., 1995; White and McKenzie, 1995] integrated with crustal thickness measurements [White and McKenzie, 1989] produce results similar to the major element studies, with high $\left(\sim 200^{\circ} \mathrm{C}\right)$ temperature excesses at hot spotinfluenced ridges.

\section{DYNAMICS OF PLUME-RIDGE INTERACTION}

\subsection{Methods of Simulating Plume-Ridge Interaction and Scaling Parameters}

[19] The evidence given in section 2 for mantle plume-ridge interaction has led to many questions regarding the driving mechanisms. For example, why does material from an off-axis plume flow against plate motion to feed a ridge axis? What controls the width that plumes flow along a ridge axis? Is plume material trans-
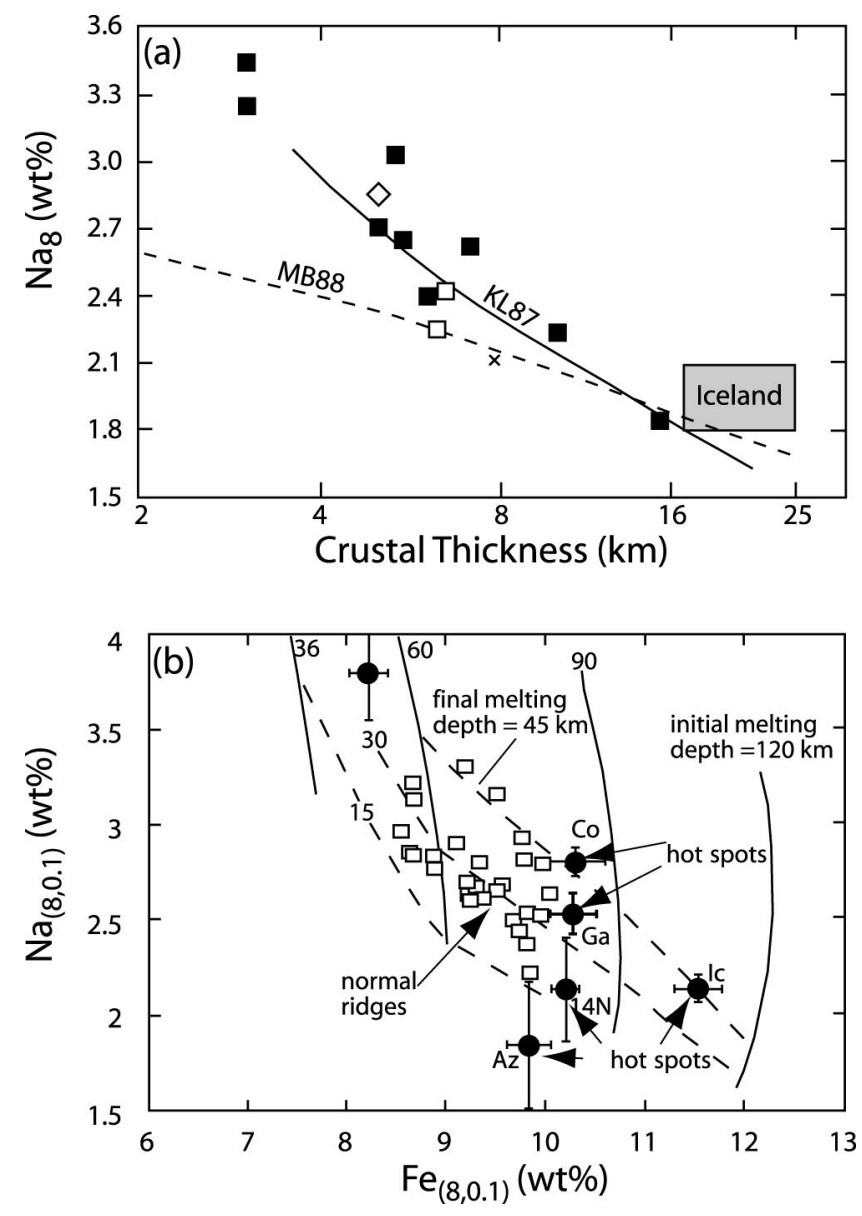

Figure 3. (a) Regional averages of crustal thickness and $\mathrm{Na}_{8}$ at various mid-ocean ridges [Langmuir et al., 1992]. The concentration of $\mathrm{Na}$ in the melt increases with the degree of low-pressure crystallization as is often measured by the melt's $\mathrm{MgO}$ content. $\mathrm{Na}_{8}$ is the concentration of $\mathrm{Na}_{2} \mathrm{O}$ in the lava after linear regression to a reference degree of crystallization or an $\mathrm{MgO}$ of $8 \%$. Differences in $\mathrm{Na}_{8}$ can therefore be attributed to differences in the parental magma prior to crystallization [Klein and Langmuir, 1987]. Dashed curve shows predictions of the melting model of Klein and Langmuir [1987], and dotted curve is the prediction of McKenzie and Bickle [1988]. (b) Negative correlation between regional averages of $\mathrm{Na}_{8,0.1}$ and $\mathrm{Fe}_{8,0.1}$ [Shen and Forsyth, 1995]. Correlations between $\mathrm{K}_{2} \mathrm{O} / \mathrm{TiO}_{2}$ and radiogenic isotope ratios suggest $\mathrm{K}_{2} \mathrm{O} / \mathrm{TiO}_{2}$ is a measure of the degree that the mantle source is enriched in incompatible elements. To correct for source compositional effects, Shen and Forsyth [1995] use correlations between $\mathrm{Na}_{8}$ and $\mathrm{Fe}_{8}$ and $\mathrm{K}_{2} \mathrm{O} / \mathrm{TiO}_{2}$ to estimate the $\mathrm{Na}_{8}$ and $\mathrm{Fe}_{8}$ content at the same reference degree of source enrichment or $\mathrm{K}_{2} \mathrm{O} / \mathrm{TiO}_{2}$ $=0.1$. These compositions are $\mathrm{Na}_{8,0.1}$ and $\mathrm{Fe}_{8,0.1}$. Curves show predicted variation for different initial (solid) and final (dashed) depths of melting as labeled.

ported toward and along mid-ocean ridges as narrow, pipe-like channels or as broad, radially expanding flows? A significant number of geodynamical studies have begun to address such questions.

[20] At large length and timescales the solid mantle deforms ductility and is often described as a viscous, 
Boussinesq fluid of zero Reynolds number. The momentum equation describes a balance between viscous stresses and gravity in each of the three orthogonal directions. For an incompressible fluid this can be expressed in tensor notation as

$$
-\nabla p+\nabla \cdot\left(\eta\left[\nabla \mathbf{u}+\nabla \mathbf{u}^{T}\right]\right)+\rho g \hat{\mathbf{z}}=0,
$$

where $\nabla p$ is the pressure gradient vector; $\eta$ is dynamic viscosity; $\nabla \mathbf{u}$ is the gradient of the velocity vector; $\nabla \mathbf{u}^{T}$ is its transpose ([Vu$\left.+\nabla \mathbf{u}^{T}\right] / 2$ is the strain rate tensor); $\rho$ is density; and $g$ is the acceleration of gravity, which acts downward (as denoted by unit vector $\hat{\mathbf{z}}$ ). Equation (1) states that in the horizontal directions, pressure gradient (first term) balances the net viscous stress acting on a small volume of fluid (second term), and in the vertical direction the first two terms also balance with the pull of gravity, $\rho g$. Density and viscosity of the Earth's mantle vary with composition, pressure, and temperature, and the temperature dependence of density is probably the dominant source of mantle plume buoyancy. The integral form of the continuity equation for incompressible flow requires zero net material flux exiting an area (infinitesimal area is vector $d \mathbf{a}$ ) enclosing a volume of the fluid (infinitesimal volume is $d V$ )

$$
\oint \mathbf{u} \cdot d \mathbf{a}=\int(\nabla \cdot \mathbf{u}) \mathrm{d} V=0 .
$$

Equations (1) and (2) comprise a system of three-dimensional (3-D) equations from which mantle flow $\mathbf{u}(x, y, z)$ is solved. Lai et al. [1993] and Turcotte and Schubert [2002], for example, provide more complete descriptions of equations (1) and (2) and their different forms.

[21] The first method of solving equations (1) and (2) uses lubrication theory to simplify the 3-D problem to describe only lateral flow of the plume in the two horizontal dimensions [Ribe et al., 1995; Ribe, 1996; Sleep, 1996; Ribe and Delattre, 1998; Yale and Phipps Morgan, 1998]. Another technique involves numerical solutions of the vertical and horizontal components of momentum and flow. In 2-D models [e.g., Kincaid et al., 1995b] the horizontal direction is perpendicular to the ridge axis, and in 3-D models [Ribe et al., 1995; Ito et al., 1996, 1997, 1999; Albers and Christensen, 2001; Ito, 2001] the alongaxis direction is also included. The two techniques are complementary: Lubrication theory methods simplify the problem to reveal the fundamental mechanisms and length scales, whereas 3-D numerical models can explore these aspects under more realistic conditions involving, for example, heat transfer, melting, and complex rheology. In addition, the dynamics of plume-ridge interaction has been explored using laboratory experiments. These experiments involve simulations in a tank filled with viscous fluid such as corn syrup [Feighner and Richards, 1995; Kincaid et al., 1995a; Jellinek et al., 2003]. Such experiments are important in verifying theoretical scaling laws and in incorporating large variations in fluid viscosity.

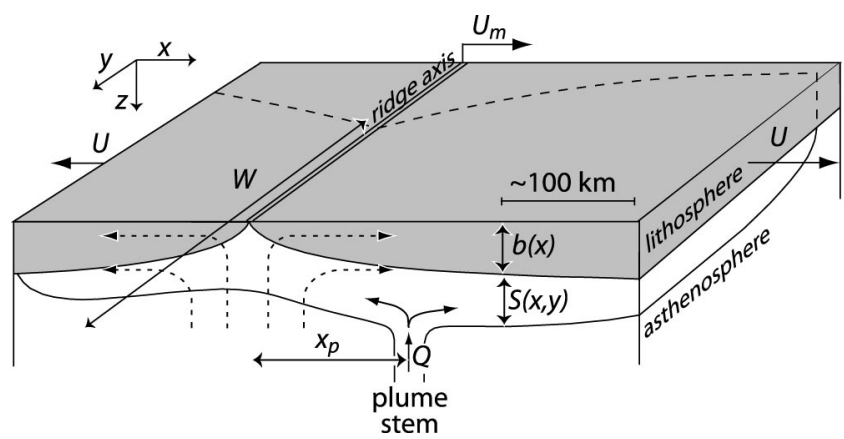

Figure 4. Cartoon illustrating the configuration and various parameters of the plume-ridge interaction model. Shortdashed curves with arrows in the cross section are a schematic illustration of the plate-driven corner flow, which would occur in the absence of the plume. Long-dashed curves in the map view show the plan form of the spreading plume. Horizontal bar shows a typical horizontal and vertical length scale. Definition of physical parameters is given in the text and Table 1.

[22] As commonly done to describe gravity currents, lubrication theory assumes the thickness of the buoyant plume layer is small compared to the lateral extent. Vertical flow due to buoyancy is thus assumed to be negligible, and equation (1) can be expressed as a balance of horizontal, hydrostatic pressure gradients, which are proportional to gradients in the thickness $S$ of the plume layer beneath the lithosphere [Olson, 1990]. Combining solutions for plate-driven corner flow and gravitational plume expansion into equation (2), Ribe [1996] derives a 2-D nonlinear diffusion-advection equation describing plume thickness $S$ near a ridge axis,

$$
\begin{aligned}
\frac{\partial S}{\partial t}=-\left(w_{c}+\right. & \left.u_{c} \frac{\partial(S+b)}{\partial x}\right)+\sigma\left(\frac{\partial^{2} S^{4}}{\partial x^{2}}+\frac{\partial^{2} S^{4}}{\partial y^{2}}\right) \\
& +4 \sigma \frac{\partial\left(S^{3} \partial b / \partial x\right)}{\partial x}+Q \delta\left(x-x_{p}\right) \delta(y) .
\end{aligned}
$$

The terms from left to right describe the time rate of change in $S$ : the rate that plate-driven upwelling $w_{c}$ and horizontal flow $u_{c}$ advect plume material; gravitational expansion of plume material; flow of plume material up the slope of a thickening lithosphere $(b$ is lithospheric thickness); and source volume flux $Q$ supplied by the plume stem, which is located at a distance $x=x_{p}$ from the ridge axis and at an arbitrary along-axis position $y=$ 0 (Figure 4 and Table 1 ) ( $\delta$ is the delta function). The "spreadability" $\sigma$ depends on plume buoyancy $\Delta \rho g$ and viscosity $\eta_{p}$ according to $\sigma=\Delta \rho g / 48 \eta_{p} ; t$ is time.

[23] Important length scales of the problem can be revealed by balancing appropriate terms in equation (3) [Ribe et al., 1995]. Balancing the advection term $\left(w_{c}\right.$ and $u_{c}$ are proportional to the half-spreading rate $U$ ) with the source term (order $Q / W_{0}^{2}$ ) reveals a scale for the width of the plume material near the ridge axis,

$$
W_{0} \equiv(Q / U)^{1 / 2} .
$$


Table 1. Physical Parameters Discussed

\begin{tabular}{|c|c|c|c|}
\hline Variable & Meaning & Value & Units \\
\hline$A$ & aspect ratio of plume isosurface as defined by the along-axis width divided by the across-axis extent & & \\
\hline$b$ & thickness of lithosphere & & $\mathrm{m}$ \\
\hline$g$ & gravitational acceleration & 9.8 & $\mathrm{~m} \mathrm{~s}^{-1}$ \\
\hline$Q$ & plume volume flux & & $\mathrm{m}^{3} \mathrm{~s}^{-1}$ \\
\hline$S$ & thickness of plume beneath lithosphere & & $\mathrm{m}$ \\
\hline$T$ & mantle temperature & & ${ }^{\circ} \mathrm{C}$ \\
\hline u & velocity vector & & $\mathrm{m} \mathrm{s}^{-1}$ \\
\hline$U$ & half-spreading rate of the plates & & $\mathrm{m} \mathrm{s}^{-1}$ \\
\hline$U_{m}$ & migration velocity of the ridge axis relative to plume in the plate spreading direction & & $\mathrm{m} \mathrm{s}^{-1}$ \\
\hline$W$ & along-axis plume width & & $\mathrm{m}$ \\
\hline$W_{0}$ & along-axis plume width scale, defined as $(Q / U)^{1 / 2}$ & & $\mathrm{~m}$ \\
\hline$w_{c}$ & vertical component of plate-driven, corner flow & & $\mathrm{m}$ \\
\hline$x_{p}$ & separation distance between plume and ridge axis & & $\mathrm{m}$ \\
\hline$\alpha$ & coefficient of thermal expansion & $3 \times 10^{-5}$ & \\
\hline$\eta$ & viscosity & & $\mathrm{Pa} \mathrm{s}$ \\
\hline$\eta_{0}$ & reference mantle viscosity away from plume & & $\mathrm{Pa} \mathrm{s}$ \\
\hline$\eta_{p}$ & plume mantle viscosity & & $\mathrm{Pa} \mathrm{s}$ \\
\hline К & thermal diffusivity & $10^{-6}$ & $\mathrm{~m}^{2} \mathrm{~s}^{-1}$ \\
\hline$\Pi_{b}$ & buoyancy number & & \\
\hline$\Pi_{c}$ & thickness ratio between lithosphere and plume layer at $x=W_{0}$ & & \\
\hline$\Pi_{u}$ & upslope number & 3300 & $\mathrm{~kg} \mathrm{~m}^{-3}$ \\
\hline$\rho$ & mantle density & & \\
\hline$\Delta \rho$ & density difference between plume and ambient mantle & & $\mathrm{kg} \mathrm{m}^{-3}$ \\
\hline$\sigma$ & plume spreadability acting as a diffusivity coefficient in equation (3) & & $\mathrm{m}^{-1} \mathrm{~s}^{-1}$ \\
\hline
\end{tabular}

Balancing the self-spreading (order $\sigma S^{4} / W_{0}^{2}$ ) and source terms reveals a scale for the thickness of the plume material,

$$
S \sim(Q / \sigma)^{1 / 4} \equiv S_{0}
$$

[24] Further analyses, which also involve 3-D numerical solutions, reveal four dimensionless quantities that control the width $W$ that plume material flows along a mid-ocean ridge. Buoyancy number $\Pi_{b}$ is a measure the of how flat the plume material is [Feighner and Richards, 1995; Ribe et al., 1995],

$$
\Pi_{b}=\left(W_{0} / S_{0}\right)^{4}=Q \sigma / U^{2} .
$$

For off-axis plumes, $x_{p} / W_{0}$ is the dimensionless ridgeplume separation. Last, the channel number $\Pi_{c}$ determines the importance of lithospheric thickness variations on plume flow. For lithosphere that thickens with the square root of age, or $b \sim(\kappa x / U)^{1 / 2}, \Pi_{c}$ is a measure of the thickness ratio between the lithosphere and plume layer at $x=W_{0}$ [Albers and Christensen, 2001],

$$
\Pi_{C} \sim\left[b\left(W_{0}\right) / S_{0}\right]^{2}=\sigma^{1 / 2} \kappa / U^{3 / 2},
$$

where $\kappa$ is thermal diffusivity.

\subsection{Results of Numerical Models}

\subsubsection{Ridge-Centered Plumes}

[25] An important contribution of recent studies is their derivation of scaling laws describing the dependence of along-axis plume width $W$ on the above quantities. A simple case to consider is a steady state plume, centered beneath a ridge axis (Figure 5). Feighner et al. [1995] introduce (compositionally) buoyant plume fluid into a numerical box, whereas Ribe et al. [1995], Ito et al. [1996], and Albers and Christensen [2001] simulate thermal buoyancy in which density is reduced relative to a reference value $\rho_{0}$ because of an excess temperature $\Delta T$ and coefficient of thermal expansion $\alpha$,

$$
\rho=\rho_{0}(1-\alpha \Delta T) \text {. }
$$

Thermal convection models also require solving the diffusion-advection equation for temperature $T$,

$$
\frac{\partial T}{\partial t}=\kappa \nabla^{2} T-\mathrm{u} \cdot \nabla T .
$$

[26] After determining $W$ for a range of plume fluxes and spreading rates, the two theoretical methods as well as laboratory experiments all find that $W$ indeed scales with $W_{0}=(Q / U)^{1 / 2}$. In addition, theoretical models predict $W$ to increase in proportion to $\Pi_{b}{ }^{\gamma}$, with $\gamma$ of the order of $10^{-2}$ [Ribe et al., 1995; Ribe, 1996; Ito et al., 1997; Albers and Christensen, 2001]. The results of a suite of 3-D numerical calculations that include a large range of spreading rates, plume fluxes, and plume ambient mantle viscosity contrasts $\left(\eta_{0} / \eta_{p}=10^{2}-10^{6}\right)$ are well fit by the scaling law (Figure 6a) [Albers and Christensen, 2001]

$$
W=(2.13 \pm 0.06)(Q / U)^{1 / 2} \Pi_{b}^{0.069 \pm 0.004} .
$$

[27] Under some conditions the thickening lithosphere can act as an inverted duct to channel plume 

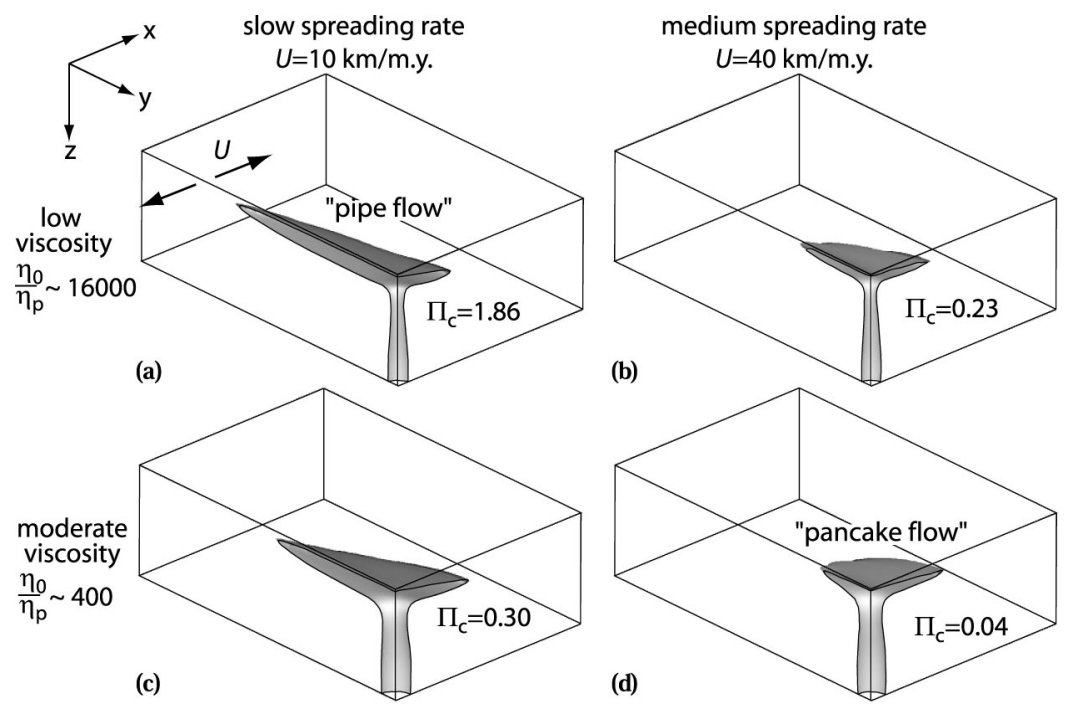

Figure 5. Illustration of four calculations of a 3-D model of plume-ridge interaction (modified from Albers and Christensen [2001]). Shaded areas are illuminated, steady state, temperature isosurfaces of plumes that have risen beneath and spread along a mid-ocean ridge. A plume is generated by imposing a circular region of excess temperature at the base of the Cartesian box. A ridge is simulated by moving the top boundary in the $x$ direction. The base and right side of the box are open boundaries. The left side (i.e., beneath ridge axis) is a reflecting boundary, and thus the model is symmetric about this plane, and the top has a no-slip and isothermal condition. Viscosity varies as an Ahrenius function of temperature and pressure, and this yields a minimum plume viscosity $\eta_{p}$ that is much lower than that of the ambient material (at a reference temperature and pressure) $\eta_{0}$. Reprinted with permission from Elsevier.

material preferentially along the ridge axis. This type of flow has been invoked to explain along-axis variations in ridge topography [Vogt, 1976] and basalt geochemistry [Schilling, 1985]. One measure of the relative rate of flow along, versus away from, the ridge axis is the aspect ratio $A$ (i.e., ratio of along-axis and across-axis extent) of an arbitrary temperature isosurface in the plume material. Albers and Christensen [2001] find $A$ to be most sensitive to channel number $\Pi_{c}$ according to (Figure $6 \mathrm{~b}$ )

$$
A=2.46 \Pi_{c}^{0.357} .
$$

Low channel numbers correspond to cases in which lithospheric thickness variations are small compared to the plume layer thickness, and thus plume flow is largely controlled by gravitational expansion and plate-driven flow. The rate of expansion is nearly axisymmetric, and the shape of the plume layer in map view is like a pancake (Figure 5d). Such flow occurs if lithospheric thickness variation is small because of a moderate or high seafloor spreading rate (Figures $5 \mathrm{~b}$ and $5 \mathrm{~d}$ ) or if plume thickness is large because of moderate viscosities (Figures $5 \mathrm{c}$ and $5 \mathrm{~d}$ ). On the contrary, high channel numbers describe cases in which lithospheric thickness variations are appreciable compared to plume thickness. In this case the "upslope" plume flow is sufficiently strong to inhibit flow away from the ridge axis and thus enhance flow along it (Figure 5a). Such "pipe flow" appears to require both low spreading rates and very low plume viscosities $\left(\sim 10^{17} \mathrm{~Pa}\right.$ s) [Albers and Christensen, 2001] (Figure 5a).

\subsubsection{Off-Axis Plumes}

[28] In the case of an off-axis plume, gravitational spreading and upslope flow cause plume material to flow toward the ridge axis, whereas plate-driven flow draws plume material away from the ridge axis (Figure 7). Both lubrication theory [Ribe, 1996] and 3-D numerical models [Ito et al., 1997] predict plume width $W$ to be maximum for the ridge-centered case (i.e., $x_{p}=0$ ) and to decrease for increasing plume-ridge separations (Figures 7 and 8). At a critical distance the flux of plume material toward the ridge axis balances the flux of platedriven flow away from the ridge. This is the maximum distance over which the plume can reach the ridge.

[29] Calculations predict $W$ to decrease as an elliptical function of $x_{p} / W_{0}$ (Figure 8),

$$
\begin{aligned}
& W=W\left(x_{p}=0\right) \\
& \cdot\left[1-C\left(\frac{x_{p}}{(Q / U)^{1 / 2} F_{2}\left(\Pi_{b}\right)\left[1-0.34 \Pi_{u}^{0.3}\right]}\right)^{2}\right]^{1 / 2},
\end{aligned}
$$

in which the term in large brackets reduces $W$ relative to the ridge-centered value $W\left(x_{p}=0\right)$ (e.g., equation (10)). Ribe [1996] finds $C=1.25$ and the function $F_{2}\left(\Pi_{b}\right)$ $\approx \Pi_{b}^{0.043}$, whereas Ito et al. [1997] find $C=1.36$ and $F_{2}\left(\Pi_{b}\right)=\Pi_{b}^{0.01}$. Ribe [1996] finds that the function [1 $\left.-0.34 \Pi_{u}^{0.3}\right]$ describes the effects of flow up the slope of a lithosphere cooling with the square root of age; the controlling parameter is a slightly different channel number, or "upslope number", $\Pi_{u}=Q^{1 / 8} \sigma^{3 / 8} \kappa^{1 / 2} / U$. For appreciable $\Pi_{u}$ the thickening lithosphere drives upslope 

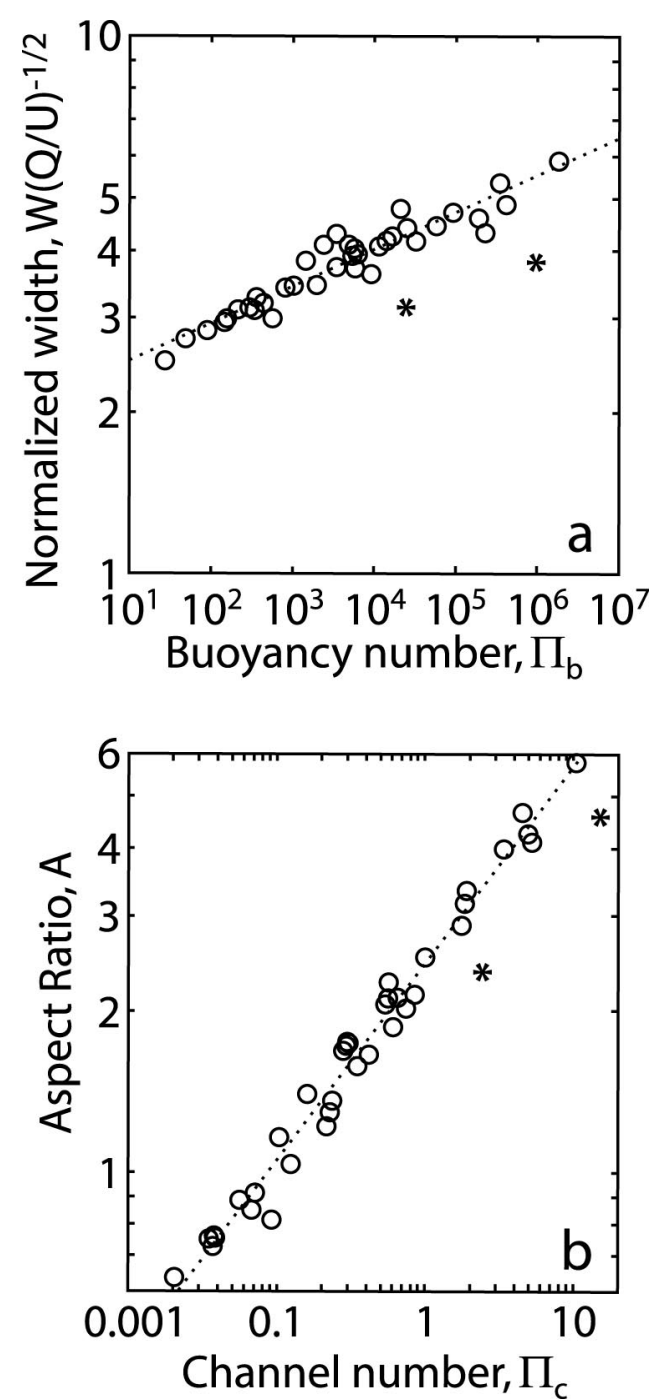

Figure 6. (a) Dependence of normalized along-axis width on buoyancy number $\Pi_{b}$ predicted by numerical models (circles) (modified from Albers and Christensen [2001]). Dotted curve is best fitting scaling law (equation (10)). (b) Aspect ratio of the plume head increasing with channel number according to the best fitting function given in equation (11) (dotted curve). In both Figures $6 \mathrm{a}$ and $6 \mathrm{~b}$, two outliers (asterisks) have been omitted in the calculation of the regression curves. These two calculations showed transient behavior unlike the steady state results of the rest of the calculations. Reprinted with permission from Elsevier.

plume flow toward the ridge but also removes material from the plume layer. For $\Pi_{u}=0.3$, for example, the result is a plume confined to a narrower extent in the along-axis direction (Figure $7 \mathrm{~b}$ ) with only a small change in $W$ compared to when $\Pi_{u}=0.0$ (Figure 7a).

\subsubsection{Ridge Migration}

[30] The final effect that we consider is ridge migration (at a rate $U_{m}$ ) in the direction perpendicular to the ridge. When a ridge is approaching the plume, the plate overlying the plume is moving at a relative rate of $U+$ $U_{m}$, whereas when a ridge is migrating away from the
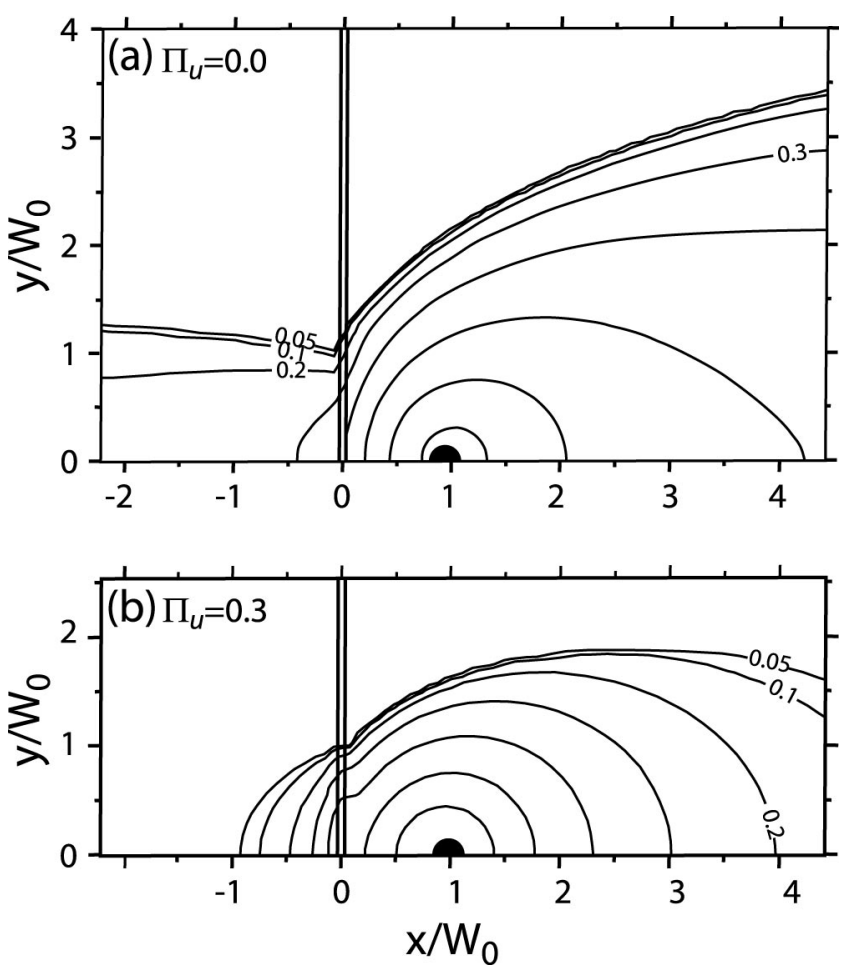

Figure 7. Contours of steady state plume layer thickness for a plume source (solid semicircle) offset from a ridge axis (vertical lines) [Ribe, 1996]. The two horizontal dimensions are normalized by $W_{0}=(Q / U)^{1 / 2}$. (a) Flat lithospheric plate with the upslope number $\Pi_{u}=0$ (modified from Figure 4 of Ribe [1996]). (b) Thickened lithosphere with the square root of distance from the ridge yielding $\Pi_{u}=0.3$ (modified from Figure 9 of Ribe [1996]).

plume the overlying plate is moving at a rate of $U-U_{m}$ (assuming plate accretion is symmetric about the ridge axis). Consequently, ridge migration is predicted to enhance or reduce plate shear on the plume depending on whether the ridge is approaching or retreating from the plume [Ito et al., 1997; Ribe and Delattre, 1998]. The predicted dependence of $W$ on $x_{p}$ is illustrated in Figure 8 . When the ridge is stationary, it does not matter which side of the ridge the plume is on, and the elliptical curve is symmetric about $x_{p}=0$. Ridge migration, however, skews the ellipse in the opposite direction of ridge migration. When the ridge is approaching the plume $\left(x_{p}>\right.$ 0 ), the ridge must be closer to the plume before plumeridge interaction can occur. In contrast, when the ridge is retreating from the plume $\left(x_{p}<0\right)$, the plume material continues to feed the ridge over greater plume-ridge separations. These predictions provide an explanation for the dominance of plume-ridge interactions involving ridges retreating from plumes [Schilling, 1985, 1991; Small, 1995].

\subsection{Evidence From Geophysical and Geochemical Observations}

[31] The above (section 3.2) geodynamic studies predict relationships that can be tested with the appropriate 


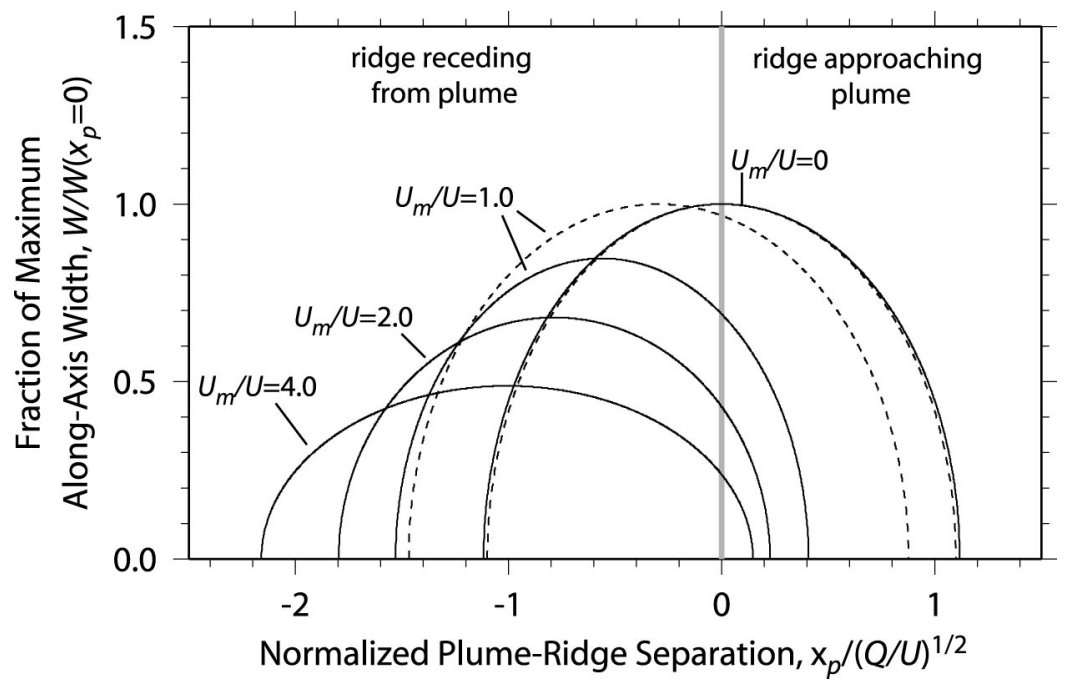

Figure 8. Predicted dependence of along-axis plume width (normalized by ridge-centered value) on plumeridge separation. Each curve shows how $W$ changes with plume-ridge separation $x_{p}$ for a single value of $U_{m} / U$ as labeled and $\Pi_{b}=10$. Solid curves are predicted by Ribe and Delattre [1998], and dashed curves are predicted by Ito et al. [1997].

geophysical and geochemical data. We first test the width scale $W_{0}=(Q / U)^{1 / 2}$. To do this, we examine along-axis widths of a number of plume-ridge systems representing a range of spreading rates. Ito and Lin [1995b] define along-axis width as the distance over which the ridge is anomalously shallow compared to a global average. In addition to present-day ridge axes, Ito and Lin [1995b] measure bathymetric anomaly widths along isochrons, with the idea that isochrons record permanent structural anomalies, such as in crustal thickness, introduced by a hot spot when each isochron was at a paleoridge axis. Figure 9a shows that, indeed, alongaxis swell widths tend to decrease and show less variability at greater spreading rates. Clearly, other factors such as volume flux $Q$ or plume-ridge separation can affect plume width, but the tendency of narrower swells at faster spreading rates lends good support for the theoretical width scale $W_{0}=(Q / U)^{1 / 2}$.

[32] Schilling [1985, 1991], on the other hand, measures along-axis widths of several near-ridge plumes by estimating the length of ridge axis with anomalously high $\mathrm{La} / \mathrm{Sm}$. His results show a less convincing inverse correlation of along-axis geochemical width with spreading rate (Figure 9a). The relationship between geochemical and bathymetric swell width is not straightforward. In some cases, such as the Marion, Galapagos, and EasterSala y Gomez hot spots, geochemical and swell widths are similar; in other cases, such as Iceland and Azores, geochemical widths are significantly less than swell widths. In the case of Tristan de Cuhna, there is no along-axis swell, but there is a short-wavelength "spikelike" anomaly seen in trace element ratios and $\mathrm{Pb}$ and He isotopes [Schilling, 1985; Hanan et al., 1986; Graham et al., 1992]. These differences suggest some decoupling between factors that contribute to swell topography, such as crustal thickness or mantle density variations, and factors that cause chemical variations, such as mantle source composition and chemical mixing.

[33] Another theoretical relation that can be tested is the predicted decrease in along-axis width with plumeridge separation distance. To minimize variations in spreading rate and plume flux, we examine a single plume-ridge system in which a history of ridge migration has provided a range of plume-ridge separations. Figure $9 \mathrm{~b}$ shows along-isochron widths of the Tristan de Cuhna hot spot swell as a function of plume-ridge separation as computed by Ito and Lin [1995b]. Plume-ridge separation was estimated from constraints on relative plate motion [Müller et al., 1993b], isochrons of Müller et al. [1993a], and the assumption that Tristan de Cuhna marks the present-day, stationary center of the plume. To ensure that along-isochron bathymetric swells record structure formed at the paleoridge axis rather than by off-axis volcanism, we considered isochrons only on the plate opposite the hot spot. Positive plume-ridge distances thus correspond to ages $\geq 80 \mathrm{Myr}$ on the African plate when the ridge was approaching the hot spot from the east, and negative distances correspond to ages $\leq 80$ Myr on the South American plate when the ridge was retreating from the plume.

[34] Indeed, along-isochron widths tend to decrease with increasing plume-ridge separation distance (Figure $9 b)$. The observations can be reasonably fit by an elliptical function similar in form to the theoretical function (12),

$$
\begin{aligned}
W= & 2.58(Q / U)^{1 / 2}\left(1-1.56\left[x_{p} /(Q / U)^{1 / 2}\right.\right. \\
& \left.\left.+0.2\left(U_{m} / U\right)^{1 / 2}\right]^{2}\right)^{1 / 2},
\end{aligned}
$$

in which an arbitrarily chosen flux of $Q=200 \mathrm{~m}^{3} \mathrm{~s}^{-1}$ and 

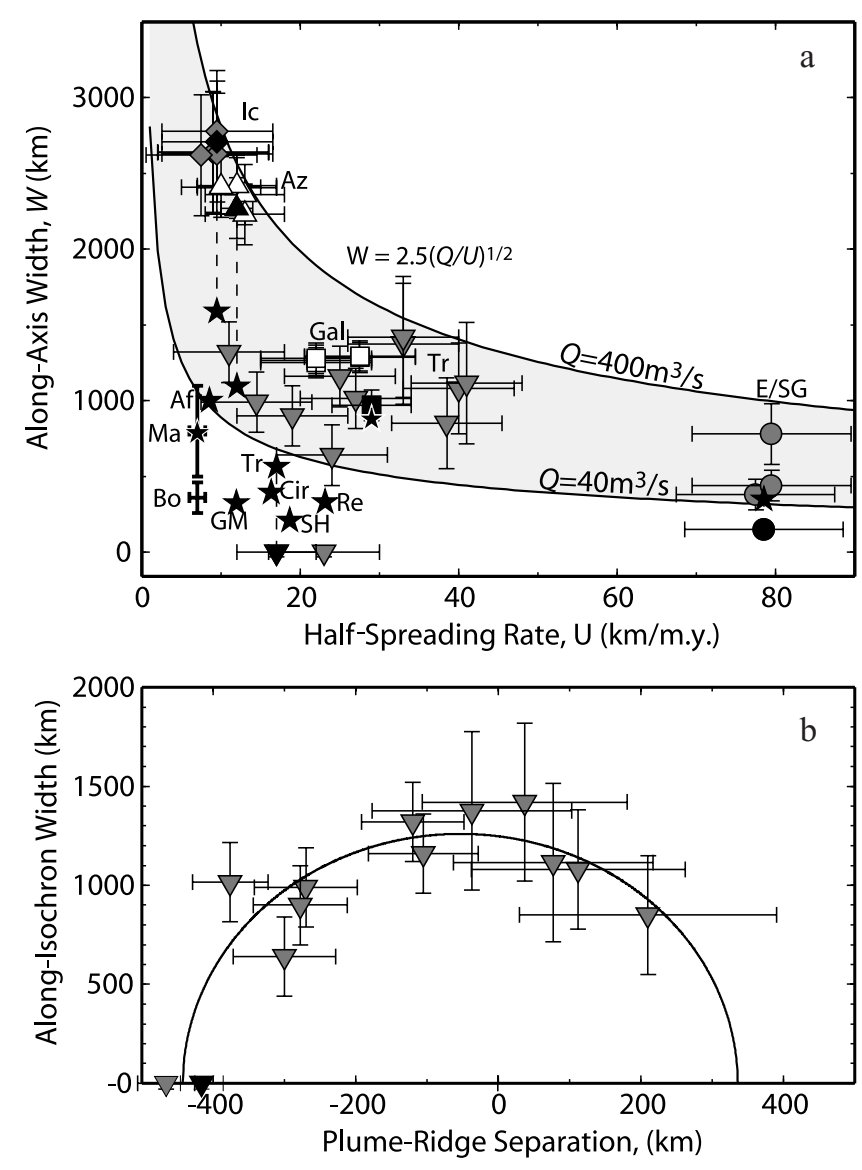

Figure 9. (a) Along-isochron widths of residual bathymetric anomalies $W$ versus half-spreading rates $U$ during times corresponding to isochron ages [Ito and Lin, 1995b]. Hot spots are represented as follows: Iceland, diamonds; Azores, open triangles; Galápagos, squares; Tristan, inverted triangles; and Easter, circles. Solid symbols mark present-day ridge axis anomalies. Bold error bars show along-axis mantle-Bouguer anomaly widths along the Southwest Indian Ridge near the Bouvet and Marion hot spots [Georgen et al., 2001]. Stars denote geochemical anomaly widths along present-day hot spots compiled by Schilling [1991]; those associated with hot spot bathymetric anomalies are connected with dashed lines. Curves show predictions of scaling laws based on lubrication theory for a range of plume volume fluxes $Q$. (b) Along-isochron widths of residual bathymetric anomalies versus plume-ridge separation distance at times corresponding to isochron ages for the TristanMAR system. Curve is best fitting elliptical function (equation (13)). Geodynamic models predict a similar elliptical function [Ribe 1996; Ito et al., 1997].

the average MAR spreading rate since $110 \mathrm{Ma}$ of $U=27$ $\mathrm{km} \mathrm{Myr}^{-1}$ [Cande and Kent, 1992] yields the width scale $W_{0}=(Q / U)^{1 / 2}=487 \mathrm{~km}$. The last term shifts the ellipse in the negative $x_{p}$ direction [Ito et al., 1997; Ribe and Delattre, 1998] and depends on the ratio $U_{m} / U$, which we estimate to average at $\sim 0.3$ over the past 110 Myr. Although the observations show scatter about the predicted elliptical function (squared correlation coefficient between $W^{2}$ and $x_{p}^{2}$ is 0.75 ) and could be fit by functions of other forms, two features support equation (13): First, the observations show weak asymmetry in which swell widths for positive $x_{p}$ are less than widths at comparable negative values of $x_{p}$; second, widths decrease more rapidly at large separations $\left(\left|x_{p}\right|>200 \mathrm{~km}\right)$ than at smaller separations $\left(0<\left|x_{p}\right|<200 \mathrm{~km}\right)$.

[35] The predicted and observational evidence for a negative curvature of $W$ versus $x_{p}$ appears to conflict with a positive curvature in geochemical width versus $x_{p}$ suggested by Schilling [1985]. This discrepancy remains unexplained, but at least two complicating factors are the poorly understood decoupling between the widths of bathymetric swells and geochemical anomalies and potentially large differences in fluxes between the different hot spots that Schilling [1985] used in his analysis. No geochemical data are currently available along seafloor isochrons of a single hot spot-ridge system.

\subsection{Models of Mantle Flow and Melting and a Ridge-Centered Mantle Plume}

[36] Besides the along-axis width of plume influence the volcanic products of plume-ridge interaction can also be used to infer certain aspects of the mantle dynamics. As discussed in section 2.3, early studies demonstrated that the volume and composition of melts at hot spotinfluenced mid-ocean ridges could be explained by mantle of high excess temperature, upwelling passively at rates comparable to plate half-spreading rates [e.g., Klein and Langmuir, 1987; McKenzie and Bickle, 1988; McKenzie and O'Nions, 1991; Langmuir et al., 1992; Shen and Forsyth, 1995; White et al., 1995; White and McKenzie, 1995]. More recent geochemical studies further support relatively slow upwelling rates in the partial melting zone beneath the Reykjanes Ridge with slightly higher upwelling rates beneath Iceland [Breddam et al., 2000; Maclennan et al., 2001; Peate et al., 2001]. Geodynamic models of 3-D convection, however, predict low-viscosity, hot mantle plumes to ascend at rates over an order of magnitude greater than plate spreading rates (Figure 10a) [Ribe et al., 1995; Ito et al., 1996]. Predicted decompression melting rates are correspondingly high, and if all melt migrates perpendicular to and accumulates at the ridge axis, a ridge-centered mantle plume would yield melt thicknesses of 60-300 km. Such thicknesses greatly exceed the seismically determined crustal thicknesses on Iceland of 20-40 km [Menke et al., 1996; Staples et al., 1997; Darbyshire et al., 1998]. The implication is that either most of the melt generated above the plume stem redistributes hundreds of kilometers along the ridge away from the plume stem or melting rates are substantially less than predicted by models of low-viscosity, high-temperature mantle plumes.

[37] Recent studies have examined the latter possibility. One possible cause for reduced upwelling and melting is an increase in viscosity associated with mantle dehydration. Hirth and Kohlstedt's [1996] analysis of peridotite deformation experiments concluded that the effective viscosity of anhydrous peridotite is much greater than that of water-saturated peridotite. The im- 


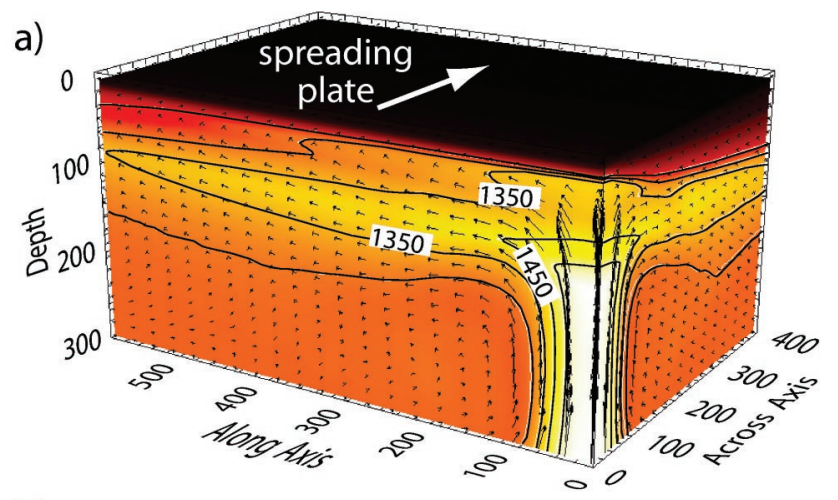

b)

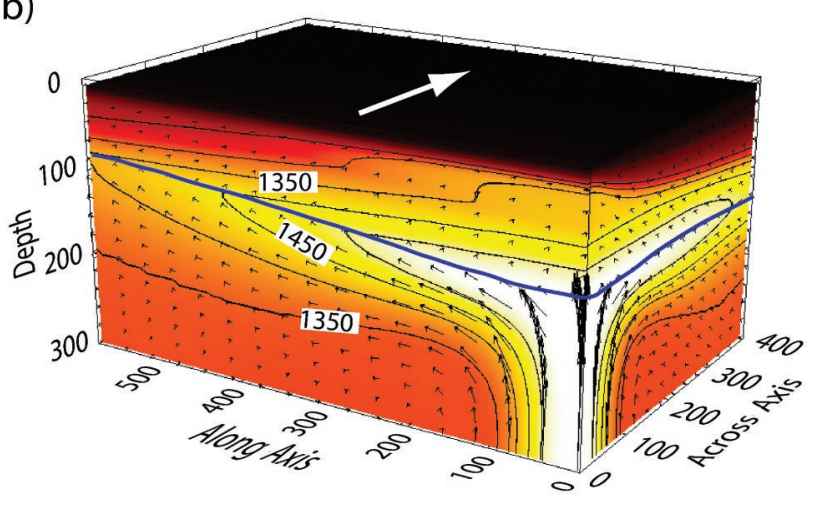

Figure 10. (a) Perspective view of 3-D numerical model of a ridge-centered plume with temperature- and pressure-dependent viscosity that includes melting. Potential temperature is colored and contoured $\left(50^{\circ} \mathrm{C}\right.$ intervals), and mantle flow direction and rate (proportional to arrow length) are shown with arrows. Maximum upwelling rate is $\sim 500 \mathrm{~km} \mathrm{Myr}^{-1}$. Box sides are reflecting boundaries, and the tops and bottoms (except in the plume) have uniform potential temperatures of $0^{\circ}$ and $1350^{\circ} \mathrm{C}$, respectively. Maximum excess temperature of $200^{\circ} \mathrm{C}$ is imposed at the center of the plume stem in the lower portion of the box. Ambient (reference) viscosity at a depth of $250 \mathrm{~km}$ is $5 \times 10^{19} \mathrm{~Pa} \mathrm{~s}$, minimum viscosity in the plume is $5.8 \times 10^{18}$ $\mathrm{Pa}$ s, and maximum viscosity in the lithosphere is $2.5 \times 10^{22} \mathrm{~Pa}$ $\mathrm{s}$. Temperature decreases in the melting zone are due to latent heat extraction. (b) Same as Figure 10a but with a viscosity increase due to the extraction of water at the base of the melting zone. Bold line marks the dry solidus and the interface above which viscosity increases by a factor of 100 .

plication is that the extraction of water $(\sim 100 \mathrm{ppm}$ in the MORB mantle source) at the onset of partial melting can lead to a large (factor of $10^{2}$ ) and rapid increase in mantle viscosity [Hirth and Kohlstedt, 1996]. Ito et al. [1999] incorporate this effect in 3-D models of a ridgecentered plume by simulating low, temperature-dependent viscosities below a dry solidus and a $10^{2}$-fold increase in average viscosity at the dry solidus. Below the dry solidus, low-viscosity plume material ascends rapidly and expands away from and along the ridge axis. Above the dry solidus where most of the melting occurs, upwelling is comparable to the MAR half-spreading rate (Figure 10b). Much like the early models of passive upwelling, melting rate is controlled predominantly by

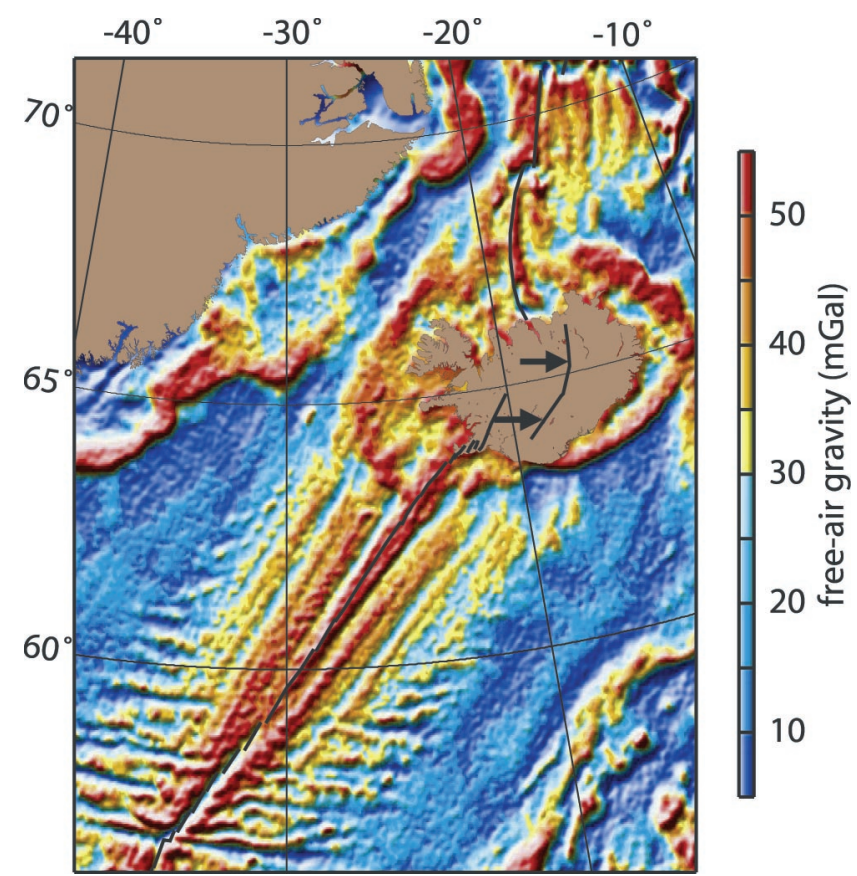

Figure 11. Map of satellite-derived free-air gravity [Sandwell and Smith, 1997] showing linear V-shaped features that straddle the Reykjanes Ridge (bold curves). Arrows show the direction of recent relocations of the axis (solid curves) of spreading at Iceland.

mantle temperature, and the predicted crustal thickness variations are consistent with seismic observations at Iceland and along the MAR (Figure 2b). This model thus combines buoyancy-driven plume expansion along the MAR beneath the melting zone with relatively slow, plate-driven upwelling in the melting zone, both of which appear to be supported by the geochemical evidence presented in section 2.3. Recent numerical models [Ito, 2001] also require this mantle dehydration boundary in order for a pulsing mantle plume to generate crustal lineations that resemble the nested, V-shaped gravity lineations straddling the MAR near Iceland and the Azores [Vogt, 1971, 1979; Cannat et al., 1999; Jones et al., 2002] (Figure 11).

\section{OUTSTANDING PROBLEMS}

\subsection{Pattern of Plume Flow: Pipes or Pancakes?}

[38] Early conceptual models of plume-ridge interaction suggested that plumes flow along and toward ridges in pipe-like channels [e.g., Vogt, 1971; Schilling, 1985; White et al., 1995; Hardarson et al., 1997] rather than in broad, pancake-like gravity currents [e.g., Ribe, 1996; Ito et al., 1997]. Fluid dynamic calculations predict channeling of plume material along a ridge axis for only low spreading rates and very low viscosity plumes [Albers and Christensen, 2001]. The implication of the mantle dehydration model is that the high-viscosity dehydrated layer minimizes the ability of the sloping, thermal lithosphere 


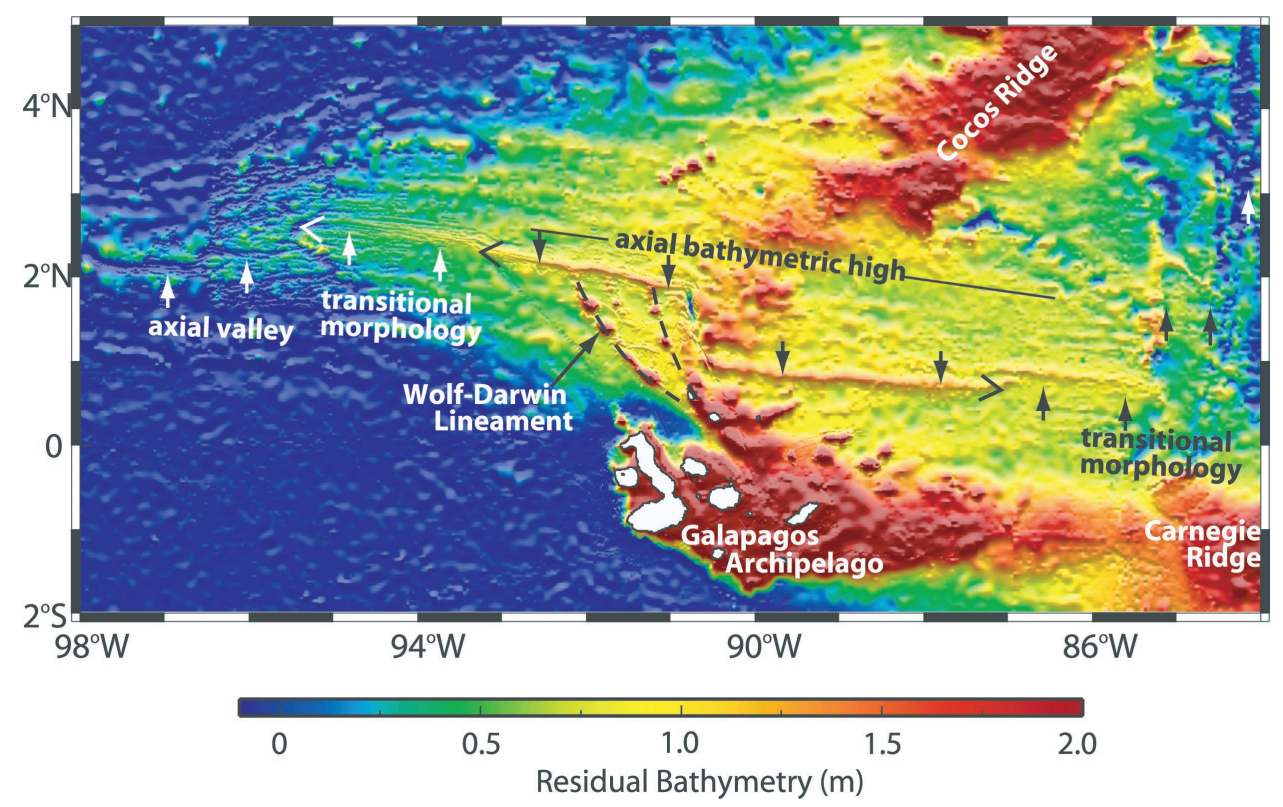

Figure 12. Residual bathymetry map of the Galapagos plume-ridge system, illuminated from the north. Vertical arrows mark ridge segments, and sideways Vs mark the tips of propagating segments. Dashed curves show volcanic lineaments.

to channel plume material along the ridge axis. The dehydrated rheological layer has a nearly uniform thickness in the across-axis direction. As a result, channel number $\Pi_{c}$ is near zero, and the hydrous plume material below expands like a pancake.

[39] Still, many geophysical and geochemical observations have been interpreted in terms of channeled plume flow. For example, inversions of surface waves recorded on Iceland show evidence for shallow asthenosphere seismic anisotropy that is consistent with substantial flow preferentially aligned with the MAR [ $L i$ and Detrick, 2003]. Also, the linearity of the V-shaped ridges on either side of the Reykjanes Ridge (Figure 11) are suggested to reflect melting anomalies migrating at a constant rate along the ridge axis [Vogt, 1976; White et al., 1995]. It has been argued that only channeled plume flow would allow for a constant along-axis flow rate. This argument, however, may be flawed because both radially expanding [Ito, 2001] and channeled plume flow [Albers and Christensen, 2001] predict along-axis flow rate to decrease with distance from a ridge-centered plume. Indeed, more detailed studies find small bends in the V-shaped ridges [Vogt, 1976; White and Lovell, 1997].

[40] Additional possible evidence for channeling of plume material along mid-ocean ridges is the apparent truncation of plume anomalies at ridge segment offsets. Geochemical anomalies along the Galapagos Spreading Center, for example, appear to be confined within the transform offsets at $95.5^{\circ} \mathrm{W}$ and $85^{\circ} \mathrm{W}$ (Figures 12 and 13) [e.g., Schilling et al., 1982; Verma and Schilling, 1982; Verma et al., 1983; Cushman et al., 2002; Detrick et al., 2002]. Likewise along the Southwest Indian Ridge, gravity anomalies of the Marion and Bouvet hot spots appear to be confined between large fracture zones [Georgen et al., 2001]. Along the Southeast Indian Ridge in the vicinity of the Amsterdam-St. Paul hot spot, high ${ }^{3} \mathrm{He} /$ ${ }^{4} \mathrm{He}$ ratios persist for the full length of the ridge segment immediately north of the Amsterdam-St. Paul Plateau, but they abruptly drop to background MORB levels at the Zeewolf transform [Graham et al., 1999]. These observations suggest that large offsets in ridge segments are capable of inhibiting or even blocking along-axis plume flow, a situation that could occur if plume flow were shallow and therefore controlled by the connectivity of a low-viscosity, subaxial channel [Georgen and Lin, 2003]. In light of this scenario the prominence of largeoffset transform faults on the Southwest Indian Ridge could explain why the along-axis widths of the Bouvet and Marion hot spots appear so low compared to widths of other hot spots at the same spreading rate (Figure 9a) [Georgen et al., 2001].

[41] In addition to channeling along a mid-ocean ridge, channeling may also occur perpendicular to midocean ridges from an off-axis plume [e.g., Schilling, 1985, 1991; Kincaid et al., 1995b; Small, 1995]. One of the most compelling arguments for channeling toward a ridge axis from an off-axis plume comes from a geochemical study of the Easter-Sala Y Gomez seamount chain and the east and west rifts of the Easter Microplate to its west [Kingsley and Schilling, 1998] (Figure 14a). Lavas along the seamount chain and at the ridge axis show lead isotope evidence $\left({ }^{206} \mathrm{~Pb} /{ }^{204} \mathrm{~Pb}\right.$ and $\left.{ }^{208} \mathrm{~Pb} /{ }^{204} \mathrm{~Pb}\right)$ for mantle flowing from the Easter-Sala Y Gomez plume toward the ridge axis. North-south variations (perpendicular to the east-west trending Easter-Sala Y Gomez seamount chain) show the highest radiogenic $\mathrm{Pb}$ near the central axis of the seamount chain with decreasing values north and south (Figure 14b). Kingsley and Schilling [1998] 

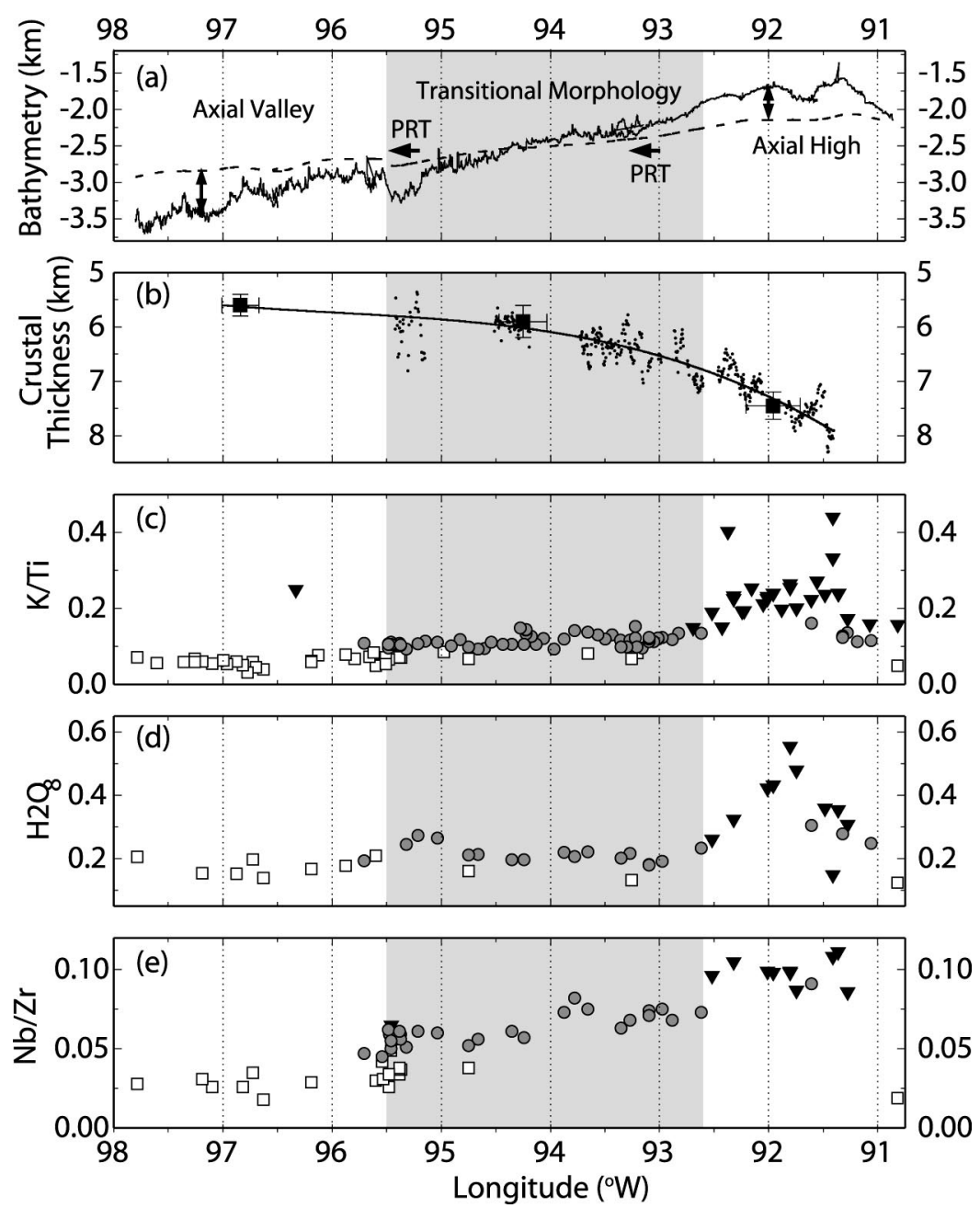

Figure 13. (a) Bathymetry along the Galapagos Spreading Center (solid curve). Dashed curve is taken along axis after filtering the raw bathymetry with a cut-off wavelength of $85 \mathrm{~km}$ [Canales et al., 2002]. This filtering removes the short-wavelength dynamic topography associated with axial morphology. The difference between the filtered and raw axial profile (small arrows) reflects the axial valley morphology west of $95.5^{\circ} \mathrm{W}$, transitional morphology (shaded), and axial high morphology east of $96.2^{\circ} \mathrm{W}$. Propagating rift tips (PRT) are marked by large arrows. (b) Crustal thickness constraints from wide-angle seismic refraction (solid squares) and multichannel seismic reflection (dots) [Canales et al., 2002]. Bold curve is best fitting smooth polynomial. (c) Incompatible element ratio $\mathrm{K} / \mathrm{Ti}$. (d) Water concentration (corrected for low-pressure crystallization as described in Figure 3 caption). (e) Incompatible element ratio $\mathrm{Nb} / \mathrm{Zr}$ measured in basalts sampled along the Galapagos Spreading Center [Detrick et al., 2002]. Triangles are enriched MORB, defined as K/Ti $>0.15$, circles are transitional MORB, defined as $0.09<\mathrm{K} / \mathrm{Ti}<0.15$, and open squares are normal MORB with $\mathrm{K} / \mathrm{Ti}$ $<0.09$. A sudden decrease in these chemical indicators at the $95.5^{\circ} \mathrm{PRT}$ suggests that this ridge segment offset may be a barrier to along-axis plume flow.

argue these north-south changes indicate a narrow plume channel ( $\sim 70 \mathrm{~km}$ wide and $\sim 650 \mathrm{~km}$ long) connecting the hot spot and ridge axis. In fact, the presence of a narrow chain of seamounts rather than a broad volcanic field is itself possible evidence for a plume channel.

[42] Volcanic lineaments between off-axis hot spots and ridges occur at other systems as well. An example is the Wolf-Darwin seamount chain extending northwest from the Galapagos Archipelago toward the Galapagos Spreading Center (Figure 12). Morgan [1978] suggests that this reflects a channel connecting the hot spot and ridge axis, but an alternative hypothesis, supported by gravity modeling [Feighner and Richards, 1994], geochronology [Sinton et al., 1996], and lithospheric stress predictions [Harpp and Geist, 2002], is that this lineament instead follows a tear in the lithosphere. Analogous volcanic lineaments are present between hot spots and ridges in the Discovery-MAR, Kerguelen-AmsterdamSt. Paul-Southeast Indian Ridge, Réunion-RodriguesCentral Indian Ridge, and Louisville-Pacific-Antarctic Ridge systems [Morgan, 1978; Small, 1995]. New studies are needed to determine whether such volcanic lineaments reflect plume channeling or discontinuities in the lithosphere, or both. 

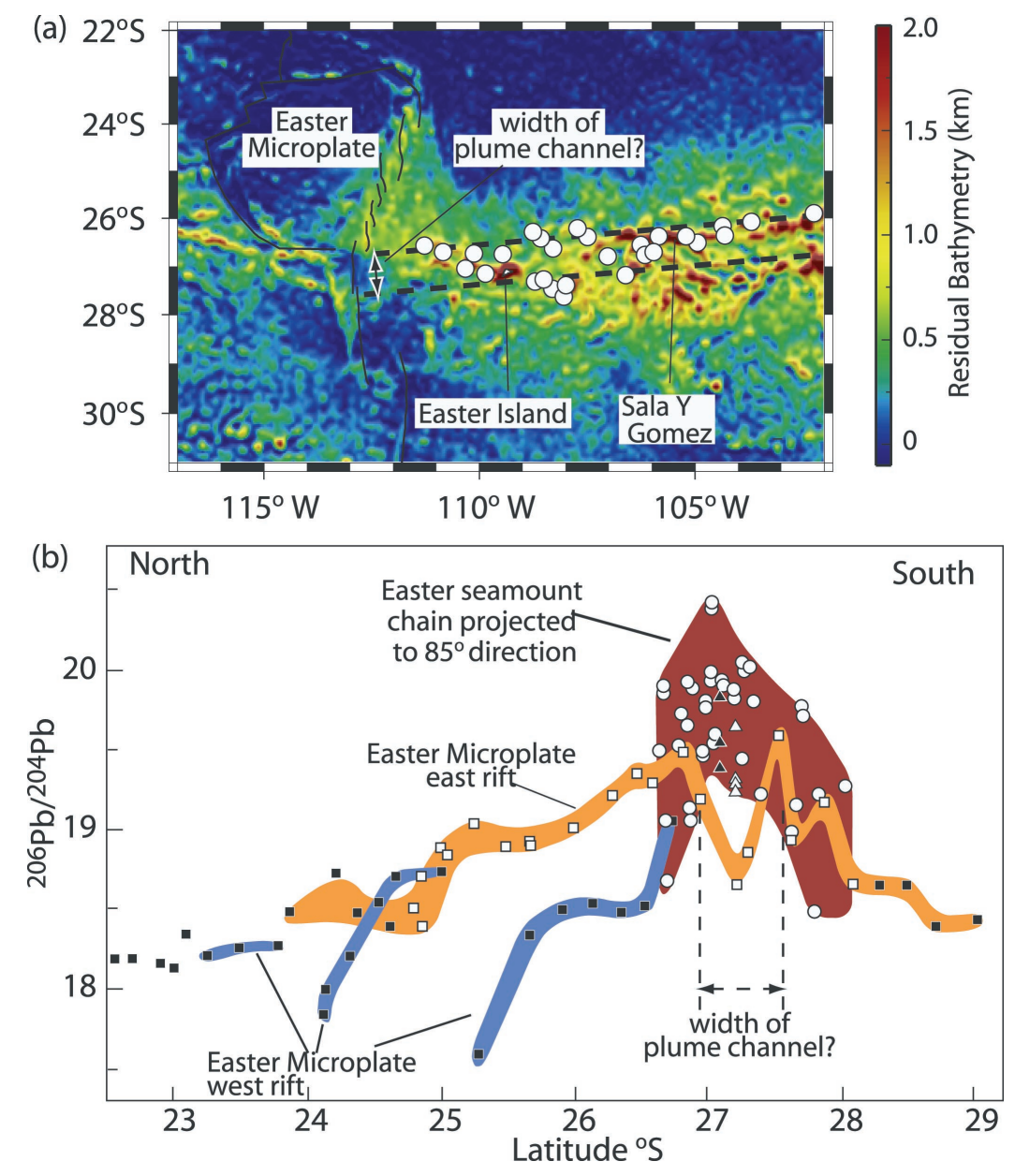

Figure 14. (a) Residual bathymetry map of the Easter-Sala Y Gomez seamount chain and the East Pacific Rise. Solid curves mark plate boundaries, and circles denote sample locations of Kingsley and Schilling [1998]. Dashed curves mark proposed narrow channel of plume flow between the off-axis hot spot and ridge axis. (b) Lead isotope ratios versus distance in latitude after projecting sample locations to an azimuth of $85^{\circ}$ (modified from Figure 2b of Kingsley and Schilling [1998]). Samples are from the Easter-Sala Y Gomez seamount chain (circles from Kingsley and Schilling [1998] and triangles from Hanan and Schilling [1989]) and east and west rift of the Easter Microplate (open and solid squares, respectively [Hanan and Schilling, 1989]). The width of the plume channel is inferred by the width over which the modeled plume component exceeds a fraction of 0.5 .

[43] One effect that may have implications on plume channeling but has not been examined by the geodynamic modeling studies discussed in section 3 is a distinction in the viscosity structure and flow between the upper and lower mantle. One proposed end-member model assumes a sufficiently high lower mantle viscosity such that the base of the upper mantle behaves as a closed boundary for upper mantle flow except in the plume stem [Yale and Phipps Morgan, 1998]. In this model the plume stem source (high pressure) feeds all of the upper mantle needed to accommodate lithospheric accretion (low pressure), and plume flow is driven only by the associated pressure gradients (plume gravitational expansion and upslope flow are ignored). Substantial plume channeling toward a ridge from an off-axis plume or along a ridge from a ridge-centered plume is therefore predicted if the plume material is significantly less viscous than the ambient upper mantle [Yale and
Phipps Morgan, 1998]. A slightly more realistic model by Sleep [1996] simulates diffuse vertical flow through the base of the upper mantle as well as gravitational expansion and upslope flow of plume material. Plume flow in this model resembles that predicted by Ribe [1996], but it begins to appear more channeled, again for very low viscosity plumes $\left(10^{17} \mathrm{~Pa} \mathrm{~s}\right)$. Whereas the models of Sleep [1996] and Yale and Phipps Morgan [1998] simplify the problem using thin-layer theory, fully 3-D numerical models are needed to more thoroughly examine plumeridge interaction in the context of both the upper and lower mantle.

[44] Geodynamic studies with very large viscosity contrasts may thus be key to determining what conditions will promote pipe versus pancake flow. To date, only Albers and Christensen [2001] have examined lateral viscosity variations exceeding $10^{3}$ and only for ridge-centered plumes. Large viscosity variations applied to off- 
ridge cases are needed to more completely address this problem. Numerical modeling is one approach, but laboratory experiments have the advantage of handling complex rheologies without the approximations that must be made with numerical methods. Laboratory experiments of Kincaid [1995a] simulate low-viscosity plumes and high-viscosity lithosphere and already suggest that variations in lithospheric topography may be more important to plume flow than predicted by numerical models. This problem of pipe versus pancake flow is important to our broader understanding of upper mantle dynamics, physical properties of the upper mantle, and the causes of hot spot-related volcanism, as well as the origin of many geochemical variations.

\subsection{Origin of Geochemical Gradients: Solid-State Versus Melt Mixing}

[45] Lava chemistry is closely linked to mass transported in the mantle and is therefore one of the best observational constraints on the dynamics of mantle flow and melting. Geochemical gradients along and perpendicular to plume-affected ridges reflect mixing between different mantle sources, but the mixing processes are rather poorly understood. A fundamental question is whether mixing occurs by stirring of solid-state mantle or by mixing of melts with different compositions. Decreases in OIB-like chemistry with distance from a hot spot could reflect progressive solid-state stirring of enriched mantle plume material with depleted ambient (MORB) mantle. Numerical models of plume-ridge interaction, however, predict very little or no stirring in the asthenosphere [Ito et al., 1996, 1997]. Plume material is predicted to simply push ambient mantle out of its way (e.g., Figures 5, 7, and 10) as the plume material expands along axis. Instead of gradual decreases in enrichment along axis, this type of model predicts a uniform, enriched composition, followed by a sudden step-like decrease in enrichment at the edge of plume influence (Figure 2d) [Ito et al., 1996, 1997]. This remains a problem.

[46] A possible solution is that the models have explored only a limited range of mantle viscosity variations and thus dynamic behaviors. Numerical models that simulate larger viscosity variations show that small-scale convective instabilities can develop in the plume layer underlying the lithosphere [Moore et al., 1998, 1999]. These instabilities grow with distance from the plume stem and therefore may lead to increased stirring of depleted ambient material into the enriched plume layer with increasing distance from the plume stem. To date, the development of small-scale instabilities has been examined at intraplate settings [Moore et al., 1998, 1999] but not near mid-ocean ridges.

[47] Alternatively, stirring may occur well below the lithosphere if plumes entrain ambient material as it rises through the mantle from its deep source [Richards and Griffiths, 1989; Hauri et al., 1994; Farnetani and Richards, 1995; Farnetani et al., 2002]. Entrainment results from outward conduction of heat and viscous shear on the sides of the plume stem. Recent numerical models, however, predict that the relative amount of entrained, in comparison to plume source material that rises to the lithosphere and melts, is likely to be small [Farnetani and Richards, 1995; Farnetani et al., 2002]. These models also predict very little actual stirring between source and entrained material for plume stems rising vertically through the mantle. On the other hand, laboratory experiments show that significant entrainment and stirring can occur if plumes are strongly deflected by horizontal flow of the ambient mantle, which could be driven by plate motion [Richards and Griffiths, 1989]. It is possible that such stirring could contribute to geochemical gradients along plume-influenced mid-ocean ridges associated with rapid absolute plate motion, such as those in the Pacific Ocean; however, it is correspondingly difficult to explain geochemical gradients along the MAR with this mechanism. Mechanisms other than solid-state stirring should therefore be explored.

[48] The other possibility is mixing between magmas. If mantle plumes are compositionally heterogeneous at small length scales, melts that arise from these heterogeneities have an opportunity to mix in different proportions depending on differences in melting depths of the heterogeneities as well as vertical variations in mantle flow and melting rate [e.g., Plank and Langmuir, 1992; Phipps Morgan, 1999; Ito and Mahoney, 2002]. For example, an enriched component in the mantle may melt deeper than a more depleted component. The rapid deep upwelling and melting predicted near a plume [Ito et al., 1999] could then result in a relatively enriched melt mixture [Ito and Mahoney, 2002]. Conversely, reduced deep melting away from a plume could lead to more depleted melt mixtures. Indeed, such effects have been proposed to induce significant trace element [Ito et al., 1999] and even isotopic variations [Schilling et al., 1999] along plume-influenced ridges.

\subsection{Effects of Plume on the Physical Structure of Mid-Ocean Ridges}

[49] Plumes also affect many physical aspects of midocean ridges including axial morphology. While most of the slow spreading MAR is associated with a broad $(10-20 \mathrm{~km})$ and deep (1-3 km) axial valley, plumeinfluenced regions, such as the Azores Plateau and the Reykjanes and Kolbeinsey Ridges near Iceland, instead show an axial topographic high. Similarly, along the intermediate spreading Galapagos Spreading Center an axial high is found over most of the plume-influenced section of the ridge, but to the west of $\sim 95^{\circ} \mathrm{W}$ an axial valley is present (Figures 12 and 13a) [Canales et al., 1997]. Lithospheric faulting forms the axial valley, the depth of which depends on the thickness of the cold, brittle lithosphere at the ridge axis [Lin and Parmentier, 1989; Chen and Morgan, 1990; Shaw, 1992]. Consequently, the presence of an axial valley or an axial high may be sensitive to ridge axis temperature, which is 
controlled by a balance of heat input by magma, and heat loss by conduction and hydrothermal circulation [Phipps Morgan and Chen, 1993; Shaw and Lin, 1996]. New seismic measurements of crustal thickness variations are beginning to quantify the amount of magma supplied to the ridge [Canales et al., 2002], thereby providing new constraints on this problem.

[50] Mantle plumes may also cause time-dependent changes in the geometry of ridge segmentation. Some hot spot-influenced ridge segments lengthen or propagate away from hot spots. Examples are segments of the Galapagos Spreading Center on either side of the Galapagos hot spot (Figure 12) [Hey et al., 1977; Hey and Vogt, 1977; Wilson and Hey, 1995], segments on the Juan de Fuca Ridge north and south of the Cobb hot spot [Hey and Wilson, 1982; Karsten and Delaney, 1989], and segments on the MAR near the Ascension and St. Helena hot spots [Brozena and White, 1990]. These lengthening ridge segments cause adjacent segments to shorten and sometimes disappear. The result is a reorganization of ridge segment geometry, tending to keep the axis of spreading near the hot spot [Wilson and Hey, 1995; Dyment, 1998]. More dramatic cases of ridge reorganization are discrete jumps in the axis of spreading toward hot spots such as those occurring on Iceland [Hardarson et al., 1997] and near the Amsterdam-St. Paul hot spot [Conder et al., 2000; Scheirer et al., 2000]. The Bouvet triple junction is another example in which a combination of ridge jumps and rift propagations may have maintained seafloor spreading near a hot spot [Ligi et al., 1999]. In fact, ridge propagations and relocations have been proposed to cause long-lived asymmetry in seafloor spreading globally [Müller et al., 1998] and may cause time dependence in the strength of plume influence on ridge axes, thereby changing the seafloor morphology over large areas of plates [Jones, 2003].

\subsection{Which Ridge Anomalies Involve Plumes and Which Do Not?}

[51] Finally, we emphasize that not all melting or geochemical anomalies along mid-ocean ridges necessarily involve mantle plumes. Some mid-ocean ridges show enrichments in incompatible elements and radiogenic isotopes but show little or no physical evidence for a magmatically robust or long-lived mantle plume. Examples include the MAR $31^{\circ}-34^{\circ} \mathrm{S}$ [Michael et al., 1994] and $14^{\circ} \mathrm{N}$ [Bougault et al., 1988], the East Pacific Rise $16^{\circ}-20^{\circ} \mathrm{S}$ [Mahoney et al., 1994], the Southern Explorer Ridge [Michael et al., 1989], and the Juan de Fuca Ridge $47^{\circ}-49^{\circ} \mathrm{N}$ [Davis and Karsten, 1986]. The lack of evidence for hot spot-like physical characteristics suggests a mechanism other than a mantle plume, possibly a "passive mantle heterogeneity" tapped fortuitously by a mid-ocean ridge.

[52] Conversely, some ridges display many physical characteristics consistent with the presence of a nearby hot spot, but the geochemical evidence for a hot mantle plume is either lacking or unclear. The Azores hot spot, for example, has a mantle source that is enriched in volatile elements [Schilling et al., 1980; Bonatti, 1990]. Volatiles, in particular water, can lower the temperature and productivity (melt fraction liberated per increment of decompression) of melting and therefore increase both the incompatible element concentration and volume of the magmas produced [e.g., Plank and Langmuir, 1992; Cushman et al., 2002; Detrick et al., 2002; Asimow and Langmuir, 2003]. These effects motivate the question of whether there is anomalously hot mantle beneath the Azores [Bonatti, 1990], although the elevated ${ }^{3} \mathrm{He} /$ ${ }^{4} \mathrm{He}$ at $38^{\circ} \mathrm{N}$ on the MAR and at the island of Terceira do support a deep mantle (plume?) influence [Moreira et al., 1999; Moreira and Allègre, 2002].

[53] The Galapagos Spreading Center is also complex in that the ridge segments with the greatest plume signal in terms of incompatible element ratios $\left(\mathrm{K}_{2} \mathrm{O} / \mathrm{TiO}_{2}\right.$ and $\mathrm{Nb} / \mathrm{Zr}$ ) and crustal thicknesses display major element evidence (e.g., $\mathrm{Na}, \mathrm{Ca}$, and $\mathrm{Al}$ ) for lower average degrees of melting compared to the ridge far from the hot spot [Schilling et al., 1982; Langmuir et al., 1992; Cushman et al., 2002; Detrick et al., 2002] (Figure 13). Again, the effects of water on melting and chemical extraction may be key [Cushman et al., 2002; Detrick et al., 2002; Asimow and Langmuir, 2003]. In addition to water, variations in mantle lithology (e.g., the presence of eclogite or garnet pyroxenite) may be important to the Galapagos and other mantle plumes [Hirschmann and Stolper, 1996; Takahashi et al., 1998]. More thorough consideration of the above compositional effects is likely to lead to revised relationships between mantle temperature and the volume and composition of melts.

[54] The Cobb hot spot near the Juan de Fuca Ridge is another intriguing case. Although the Cobb-Eickelberge seamount chain shows a geographic age progression, eventually intersecting the Juan de Fuca Ridge [Duncan and Clague, 1985; Smoot, 1985], isotope compositions obtained from the seamount chain [Desoine and Duncan, 1990] and adjacent portions of the Juan de Fuca Ridge are inconsistent with an enriched mantle plume source [Eaby et al., 1984; Lupton et al., 1993]. Is there a Cobb-Eickelberge mantle plume tapping a mantle geochemical reservoir different from other plumes? Or is there an alternative mechanism responsible for the excess volcanism? Different hot spot-ridge systems fit the simple model of mantle plume-ridge interaction to varying degrees of success. It is thus important to continually question the involvement of plumes in hot spotridge interactions, seeking new information to test for plumes, while searching out improved or alternative descriptions of these systems.

[55] Indeed, we face important challenges in addressing the outstanding problems. Many regions of seafloor associated with hot spot-ridge systems, especially the off-axis regions, have yet to be surveyed and sampled. The most direct means of constraining physical aspects of the mantle such as temperature, distribution of melt, and pattern of flow are mantle seismic and electromag- 
netic methods, and technological advances in these methods are providing new constraints on mantle structure and flow [Nolasco et al., 1998; The MELT Seismic Team, 1998; Evans et al., 1999; Gaherty, 2001; Allen et al., 2002]. In addition, improvements in analytical techniques and instrumentation, most notably the advent of multicollector inductively coupled plasma-mass spectrometry, and ion microprobe techniques for in situ chemical analyses of crystals and melt inclusions are providing unprecedented chemical and isotopic measurements that are central to constraining ascent rates of mantle and magma along with the chemical history of the mantle [e.g., Sims et al., 1995; Saal et al., 1998; Peate et al., 2001]. Finally, rapidly increasing computing power is enhancing our ability to numerically solve complex problems related to mantle flow and melting at increasing resolution. Together, the geophysical and geochemical community is well poised to make significant advances in understanding hot spot-ridge interactions.

\section{CONCLUSIONS}

[56] Three decades of research have built a sound framework for understanding the physical and chemical dynamics of hot spot-ridge interaction. Ridge interactions with hot and compositionally distinct mantle plumes are supported by geophysical evidence for thickened crust, anomalously low mantle density, and anomalous mantle seismic structure, as well as geochemical evidence for chemical heterogeneity, elevated degrees of melting, and increased pressures of melting. Laboratory experimental and geodynamic modeling studies have contributed to a basic understanding of the fluid dynamics of plume-ridge interaction. Gravitationally driven expansion of buoyant plume material, viscous shear of plate spreading, lithospheric thickness variations, plume-ridge separation, and relative motion between ridges and plumes are all important factors in controlling plume-ridge interactions

[57] Several key questions remain, including those related to the pattern and distribution of plume flow, the mechanism by which plume and ambient material mixes, the way mantle plumes affect the morphology and geometry of mid-ocean ridge segments, the effects of volatiles on mantle flow and melting, and the origin of ridge anomalies that may not be related to mantle plumes. More complete understanding of such problems must come from an integration of geophysical, geochemical, and geodynamic modeling approaches. Indeed, addressing these problems has broader importance for our understanding of the many basic physical and chemical processes associated with volcanism on Earth.

\section{GLOSSARY}

Hot spot: A region of elevated topography spanning hundreds of kilometers to over a thousand kilome- ters and capped with volcanoes. Volcanism is often oriented in lines or chains and tends to become younger toward one end of the chain. This geographic age progression defines a location in the mantle that is fixed relative to the migrating plate [Wilson, 1963; Morgan, 1971, 1972]. Some hot spots may be caused by mantle plumes [Morgan, 1971], and some are likely to have other origins. This topic continues to be debated. Hot spots have been identified in the oceans as well as on continents; this paper will emphasize oceanic hot spots.

Incompatible element: A chemical element that is less concentrated in the solid than in melt when the two phases are in equilibrium. Incompatible elements are therefore preferentially extracted from the mantle upon partial melting.

Mantle plume: An anomalously hot and buoyant mantle upwelling, originating as a convective instability from a hot thermal boundary layer, originally envisioned but not necessarily restricted to be the core-mantle boundary. A "mantle plume" is a hypothesized mechanism to form "hot spots."

MORB: Mid-ocean ridge basalt, used to characterize the composition of basalts commonly erupted at "normal" mid-ocean ridges unaffected by plumes. MORBs are relatively depleted in incompatible trace elements and exhibit radiogenic isotope compositions, indicating that this depletion is ancient.

OIB: Ocean island basalt, used to characterize the chemistry of basalts commonly erupted at ocean islands associated with hot spots. Compared to MORBs, OIBs span a larger range in composition, extending to compositions more enriched in incompatible elements with radiogenic isotope concentrations reflecting a long-term enrichment.

Passive mantle heterogeneity: Conceptualized as a relatively small (tens to hundreds of kilometers in lateral dimension) body of mantle, enriched in incompatible elements. The density anomaly of the body is weak or nonexistent; therefore the body is thought to migrate passively with the surrounding mantle. Such bodies may be tapped by mid-ocean ridge melting to give a crustal thickness and/or geochemical anomaly that is shortlived.

[58] ACKNOWLEDGMENTS. The integration of various studies reviewed here benefited from many talks and abstracts presented at the August 2000 RIDGE/NordVulk Iceland Summer School in Lake Myvatn, Iceland, and the June 2000 RIDGE Workshop in Oregon, United States. Presentations by R. S. Detrick, N. Ribe, J. M. Sinton, and W. M. White at these workshops were particularly helpful. We appreciate reviews contributed by associate editor L. Kellogg and two anonymous referees. G. Ito was funded by NSF grants OCE-0002189 and OCE-0221889 and new faculty start-up funds contributed by SOEST. J. Lin was supported by NSF grant OCE-0129741 and the Andrew W. Mellon Foundation Endowed Fund for Innovative Research at WHOI. This is SOEST contribution num- 
ber 6208 and WHOI contribution number 10945.

[59] Louise Kellogg is the Editor responsible for this paper. She thanks two technical reviewers and one cross-disciplinary reviewer.

\section{REFERENCES}

Albers, M., and U. R. Christensen, Channeling of plume flow beneath mid-ocean ridges, Earth Planet. Sci. Lett., 187, 207-220, 2001.

Allen, R. M., et al., The thin hot plume beneath Iceland, Geophys. J. Int., 137, 51-63, 1999.

Allen, R. M., et al., Imaging the mantle beneath Iceland using integrated seismological techniques, J. Geophys. Res., 107(B12), 2325, 10.1029/2001JB000595, 2002.

Anderson, D. L., Enriched asthenosphere and depleted plumes, Int. Geol. Rev., 38, 1-21, 1996.

Armstrong, R. L., Radiogenic isotopes: The case for crustal recycling on a near steady-state no-continental growth Earth, Philos. Trans. R. Soc. London, Ser. A, 301, 443-472, 1981.

Asimow, P., and C. H. Langmuir, The importance of water to oceanic melting regimes, Nature, 421, 815-820, 2003.

Bijwaard, H., and W. Spakman, Tomographic evidence for a narrow whole mantle plume below Iceland, Earth Planet. Sci. Lett., 166, 121-126, 1999.

Bjarnason, I. T., W. Menke, Ó. Flóvenz, and D. Caress, Tomographic image of the Mid-Atlantic plate boundary in southwest Iceland, J. Geophys. Res., 98, 6607-6622, 1993.

Bonatti, E., Not so hot "hot spots" in the oceanic mantle, Science, 250, 107-110, 1990.

Bougault, H., L. Dmitriev, J.-G. Schilling, A. Sobolev, J. L. Joron, and H. D. Needham, Mantle heterogeneity from trace elements: MAR triple junction near $14^{\circ} \mathrm{N}$, Earth Planet. Sci. Lett., 88, 27-36, 1988.

Breddam, K., M. D. Kurz, and M. Storey, Mapping out the conduit of the Iceland mantle plume with helium isotopes, Earth Planet. Sci. Lett., 176, 45-55, 2000.

Brozena, J. M., and R. S. White, Ridge jumps and propagations in the South Atlantic Ocean, Nature, 348, 149-152, 1990.

Bunch, A. W. H., and B. L. N. Kennett, The crustal structure of the Reykjanes Ridge at $59^{\circ} 30^{\prime} \mathrm{N}$, Geophys. J. R. Astron. Soc., 61, 141-166, 1980.

Canales, J. P., J. J. Danobeitia, R. S. Detrick, E. E. E. Hooft, R. Barolomé, and D. Naar, Variations in axial morphology along the Galápagos Spreading Center and the influence of the Galápagos hotspot, J. Geophys. Res., 102, 27,341-27,354, 1997.

Canales, J. P., G. Ito, R. Detrick, and J. Sinton, Crustal thickness along the western Galápagos spreading center and the compensation of the Galápagos hotspot swell, Earth Planet. Sci. Lett., 203, 311-327, 2002.

Cande, S. C., and D. V. Kent, A new geomagnetic polarity time scale for the Late Cretaceous and Cenozoic, J. Geophys. Res., 97, 13,917-13,951, 1992.

Cannat, M., et al., Mid-Atlantic Ridge-Azores hotspot interactions: Along-axis migration of a hotspot-derived event of enhanced magmatism 10 to $4 \mathrm{Ma}$ ago, Earth Planet. Sci. Lett., 173, 257-269, 1999.

Chen, Y., and W. J. Morgan, Rift valley/no rift valley transition at mid-ocean ridges, J. Geophys. Res., 95, 17,571-17,581, 1990.

Coffin, M. F., and L. M. Gahagan, Ontong Java and Kerguelen Plateaux: Cretaceous Icelands?, J. Geol. Soc. London, 152, 1047-1052, 1995.

Conder, J. A., D. S. Scheirer, and D. W. Forsyth, Seafloor spreading on the Amsterdam-St. Paul hotspot plateau, J.
Geophys. Res., 105, 8263-8277, 2000.

Cushman, B. J., J. M. Sinton, G. Ito, and J. E. Dixon, Hydrous melting creates lower mean $\mathrm{F}$ at the Galapagos spreading Center-Modeling results from a major and volatile elements study, Eos Trans. AGU, 83(47), Fall Meeting Suppl., Abstract S71D-06, 2002.

Darbyshire, F. A., I. T. Bjarnason, R. S. White, and O. G. Flovenz, Crustal structure above the Iceland mantle plume imaged by the ICEMELT refraction profile, Geophys. J. Int., 135, 1131-1149, 1998.

Darbyshire, F. A., R. S. White, and K. F. Priestley, Structure of the crust and uppermost mantle of Iceland from a combined seismic and gravity study, Earth Planet. Sci. Lett., 181, 409-428, 2000.

Davis, E. E., and J. L. Karsten, On the cause of the asymmetric distribution of seamounts about the Juan de Fuca Ridge: Ridge-crest migration over a heterogeneous asthenosphere, Earth Planet. Sci. Lett., 79, 385-396, 1986.

Desoine, D. L., and R. A. Duncan, The Cobb-Eickelberg seamount chain: Hotspot volcanism with mid-ocean ridge basalt affinity, J. Geophys. Res., 95, 12,697-12,711, 1990.

Detrick, R. S., J. M. Sinton, G. Ito, J. P. Canales, M. Behn, T. Blacic, B. Cushman, J. E. Dixon, D. W. Graham, and J. Mahoney, Correlated geophysical, geochemical and volcanological manifestations of plume-ridge interaction along the Galápagos Spreading Center, Geochem., Geophys., Geosys., 3(10), 8501, doi:10.1029/2002GC000350, 2002.

Duncan, R. A., and D. A. Clague, Pacific plate motion recorded by linear volcanic chains, in The Ocean Basins and Margins, edited by A. E. M. Nairn, F. G. Stehli, and S. Uyeda, pp. 89-121, Plenum, New York, 1985.

Dyment, J., Evolution of the Carlsberg Ridge between 60 and 45 Ma: Ridge propagation, spreading asymmetry, and the Deccan-Reunion hotspot, J. Geophys. Res., 103, 24,06724,084, 1998.

Eaby, J., D. A. Clague, and J. R. Delaney, Sr isotopic variations along the Juan de Fuca Ridge, J. Geophys. Res., 89, 78837890, 1984.

Evans, R. L., et al., Asymmetric electical structure in the mantle beneath the East Pacific Rise at $17^{\circ} \mathrm{S}$, Science, 286, 752-756, 1999.

Eysteinsson, H., and K. Gunnarsson, Maps of gravity, bathymetry and magnetics for Iceland and surroundings, Rep. OS95055/JHD-07, Orkustofnun Natl. Energy Auth. Geothermal Div., Reykjavik, 1995.

Farnetani, C. G., and M. A. Richards, Thermal entrainment and melting in mantle plumes, Earth Planet. Sci. Lett., 133, 251-267, 1995.

Farnetani, C. G., B. Legras, and P. J. Tackley, Mixing and deformations in mantle plumes, Earth Planet. Sci. Lett., 196, 1-15, 2002.

Feighner, M. A., and M. A. Richards, Lithospheric structure and compensation mechanisms of the Galápagos Archipelago, J. Geophys. Res., 99, 6711-6729, 1994.

Feighner, M. A., and M. A. Richards, The fluid dynamics of plume-ridge and plume-plate interactions: An experimental investigation, Earth Planet. Sci. Lett., 129, 171-182, 1995.

Feighner, M. A., L. H. Kellogg, and B. J. Travis, Numerical modeling of chemically buoyant mantle plumes at spreading ridges, Geophys. Res. Lett., 22, 715-718, 1995.

Foulger, G. R., et al., Seismic tomography shows that upwelling beneath Iceland is confined to the upper mantle, Geophys. J. Int., 146, 504-530, 2001.

Gaherty, J. B., Seismic evidence for hotspot-driven buoyant upwelling beneath the Reykjanes Ridge, Science, 293, 16451647, 2001.

Georgen, J., and J. Lin, Plume-transform interactions at ultraslow spreading rates: Implications for the Southwest Indian Ridge, Geochem. Geophys. Geosys., 4(9), 9106, doi:10.1029/ 
2003GC000542, 2003.

Georgen, J. E., J. Lin, and H. J. B. Dick, Evidence from gravity anomalies for interactions of the Marion and Bouvet hotspots with the Southwest Indian Ridge: Effects of transform offsets, Earth Planet. Sci. Lett., 187, 283-300, 2001.

Graham, D. W., Noble gas isotope geochemistry of mid-ocean ridge and ocean island basalts: Characterization of mantle source reservoirs, in Noble Gases in Geochemistry and Cosmochemistry, edited by D. Porcelli, C. J. Ballentine, and R. Wieler, pp. 247-318, Mineral. Soc. of Am., Washington, D. C., 2002.

Graham, D. W., W. J. Jenkins, J.-G. Schilling, and S. E. Humphris, Helium isotope geochemistry of mid-ocean ridge basalts from the South Atlantic, Earth Planet. Sci. Lett., 110, 133-147, 1992.

Graham, D., K. T. M. Johnson, L. D. Priebe, and J. E. Lupton, Hotspot-ridge interaction along the Southeast Indian Ridge near Amsterdam and St. Paul Islands: Helium isotope evidence, Earth Planet. Sci. Lett., 167, 297-310, 1999.

Hanan, B. B., and D. W. Graham, Lead and helium isotope evidence from oceanic basalts for a common deep source of mantle plumes, Science, 272, 991-995, 1996.

Hanan, B. B., and J.-G. Schilling, Easter Microplate evolution: $\mathrm{Pb}$ isotope evidence, J. Geophys. Res., 94, 7432-7448, 1989.

Hanan, B. B., R. H. Kingsley, and J.-G. Schilling, Pb isotope evidence in the South Atlantic for migrating ridge-hotspot interactions, Nature, 322, 137-144, 1986.

Hardarson, B. S., J. G. Fitton, R. M. Ellam, and M. S. Pringle, Rift relocation-A geochemical and geochronological investigation of a paleo-rift in northwest Iceland, Earth Planet. Sci. Lett., 153, 181-196, 1997.

Harpp, K., and D. Geist, Wolf-Darwin lineament and plumeridge interaction in northern Galapagos, Geochem. Geophys. Geosyst., 3(11), 8504, doi:10.1029/2002GC000370, 2002.

Hart, S. R., J.-G. Schilling, and J. L. Powell, Basalts from Iceland and along the Reykjanes Ridge: $\mathrm{Sr}$ isotope geochemistry, Nature Phys. Sci., 246, 104-107, 1973.

Hart, S. R., E. H. Hauri, L. A. Oschmann, and J. A. Whitehead, Mantle plumes and entrainment: Isotopic evidence, Science, 256, 517-520, 1992.

Hauri, E. H., J. A. Whitehead, and S. R. Hart, Fluid dynamics and geochemical aspects of entrainment in mantle plumes, J. Geophys. Res., 99, 24,275-24,300, 1994.

Hemond, C., N. T. Arndt, U. Lichtenstein, and A. W. Hofmann, The heterogeneous Iceland plume: $\mathrm{Nd}-\mathrm{Sr}-\mathrm{O}$ isotopes and trace element constraints, J. Geophys. Res., 98, 15,83315,850, 1993.

Hey, R. N., and P. J. Vogt, Spreading center jumps and subaxial asthenospheric flow near the Galapagos hot spot, Tectonophysics, 37, 41-52, 1977.

Hey, R. N., and D. S. Wilson, Propagating rift explanation for the tectonic evolution of the northeast Pacific-The pseudomovie, Earth Planet. Sci. Lett., 58, 167-188, 1982.

Hey, R., G. L. Johnson, and A. Lowrie, Recent plate motions in the Galapagos area, Geol. Soc. Am. Bull., 88, 1385-1403, 1977.

Hirschmann, M. M., and E. M. Stolper, A possible role for garnet pyroxenite in the origin of the "garnet signature" in MORB, Contrib. Mineral. Petrol., 124, 185-208, 1996.

Hirth, G., and D. L. Kohlstedt, Water in the oceanic upper mantle: Implications for rheology, melt extraction, and the evolution of the lithosphere, Earth Planet. Sci. Lett., 144, 93-108, 1996.

Hofmann, A. W., and W. M. White, Mantle plumes from ancient oceanic crust, Earth Planet. Sci. Lett., 57, 421-436, 1982.

Honda, M., I. McDougall, and D. Patterson, Solar noble gases in the Earth: The systematics of helium-neon isotopes in mantle derived samples, Lithos, 30, 257-265, 1993.

Ito, G., Reykjanes 'V'-shaped ridges originating from a pulsing and dehydrating mantle plume, Nature, 411, 681-684, 2001.

Ito, G., and J. Lin, Mantle temperature anomalies along the present and paleoaxes of the Galápagos Spreading Center as inferred from gravity analyses, J. Geophys. Res., 100, 3733-3745, 1995a.

Ito, G., and J. Lin, Oceanic spreading center-hotspot interactions: Constraints from along-isochron bathymetric and gravity anomalies, Geology, 23, 657-660, 1995 b.

Ito, G., and J. J. Mahoney, Effects of variable productivity and active mantle of upwelling on trace-elements and isotopic composition of hotspot magmas, Eos Trans. AGU, 83(47), Fall Meeting Suppl., Abstract S71D-06, 2002.

Ito, G., J. Lin, and C. W. Gable, Dynamics of mantle flow and melting at a ridge-centered hotspot: Iceland and the MidAtlantic Ridge, Earth Planet. Sci. Lett., 144, 53-74, 1996.

Ito, G., J. Lin, and C. Gable, Interaction of mantle plumes and migrating mid-ocean ridges: Implications for the Galápagos plume-ridge system, J. Geophys. Res., 102, 15,403-15,417, 1997.

Ito, G., Y. Shen, G. Hirth, and C. Wolfe, Mantle flow, melting, and dehydration of the Iceland mantle plume, Earth Planet. Sci. Lett., 165, 81-96, 1999.

Jellinek, A. M., H. M. Gonnermann, and M. A. Richards, Plume capture by divergent plate motions: Implications for the distribution of hotspots, geochemistry of mid-ocean ridge basalts, and heat flux at the core-mantle boundary, Earth Planet. Sci. Lett., 205, 367-378, 2003.

Jones, S. M., Test of a ridge-plume interaction model using oceanic crustal structure around Iceland, Earth Planet. Sci. Lett., 208, 205-218, 2003.

Jones, S. M., N. White, and J. Maclennan, V-shaped ridges around Iceland: Implications for spatial and temporal patterns of mantle convection, Geochem. Geophys. Geosys., 3(10), 1059, 10.1029/2002GC000361, 2002.

Karsten, J. L., and J. R. Delaney, Hot spot-ridge crest convergence in the northeast Pacific, J. Geophys. Res., 94, 700-712, 1989.

Kellogg, L. H., B. Hager, and R. van der Hilst, Compositional stratification in the deep mantle, Science, 99, 276-289, 1999.

Kincaid, C., G. Ito, and C. Gable, Laboratory investigation of the interaction of off-axis mantle plumes and spreading centres, Nature, 376, 758-761, 1995a.

Kincaid, C., J.-G. Schilling, and C. Gable, The dynamics of off-axis plume-ridge interaction in the uppermost mantle, Earth Planet. Sci. Lett., 137, 29-43, 1995b.

Kingsley, R. H., and J.-G. Schilling, Plume-ridge interaction in the Easte-Salas y Gomez seamount chain-Easter Microplate system: $\mathrm{Pb}$ isotope evidence, J. Geophys. Res., 103, 24,150-24,177, 1998.

Klein, E. M., and C. H. Langmuir, Global correlations of ocean ridge basalt chemistry with axial depth and crustal thickness, J. Geophys. Res., 92, 8089-8115, 1987.

Kodaira, S., R. Mjelde, K. Gunnarsson, H. Shiobara, and H. Shimamura, Crustal structure of the Kolbeinsey Ridge, North Atlantic, obtained by use of ocean bottom seismographs, J. Geophys. Res., 102, 3131-3151, 1997.

Kurz, M. D., W. J. Jenkins, and S. R. Hart, Helium isotopic systematics of ocean islands and mantle heterogeneity, $\mathrm{Na}$ ture, 297, 43-47, 1982.

Kurz, M. K., Noble gas isotopes in oceanic basalts: Controversial constraints on mantle models, in Short Course Handbook on Applications of Radiogenic Isotope Systems to Problems in Geology, edited by L., Heaman and J. N. Ludden, pp. 259-286, Mineral. Assoc. of Can., Toronto, Ont., Canada, 1991.

Lai, W. M., D. Rubin, and E. Krempl, Introduction to Continuum Mechanics, 556 pp., Butterworth-Heinemann, 
Woburn, Mass., 1993.

Langmuir, C. H., and G. N. Hanson, An evaluation of major element heterogeneity in the mantle sources of basalts, Philos. Trans. R. Soc. London, Ser. A, 297, 383-407, 1980.

Langmuir, C. H., E. M. Klein, and T. Plank, Petrological systematics of mid-ocean ridge basalts: Constraints on melt generation beneath ocean ridges, in Mantle Flow and Melt Generation at Mid-Ocean Ridges, Geophys. Monogr. Ser., vol. 71, edited by J. Phipps Morgan, D. K. Blackman, and J. M. Sinton, pp. 183-280, AGU, Washington, D. C., 1992.

Laske, G., and G. Masters, A global digital map of sediment thickness (abstract), Eos Trans. AGU, Fall Meeting Suppl., 78(46), F483, 1997.

Li, A., and R. S. Detrick, Azimuthal anisotropy and phase velocity beneath Iceland: Implication for plume-ridge interaction, Earth Planet. Sci. Lett., in press, 2003.

Ligi, M., E. Bonatti, G. Bortoluzzi, G. Carrara, P. Fabretti, D. Gilod, A. A. Peyve, S. Skolotnev, and N. Turko, Bouvet Triple Junction in the South Atlantic: Geology and evolution, J. Geophys. Res., 104, 29,365-29,385, 1999.

Lin, J., and E. M. Parmentier, Mechanisms of lithospheric extension at mid-ocean ridges, Geophys. J., 96, 1-22, 1989.

Lupton, J. E., Terrestrial intert gases: Isotope tracer studies and clues to primordial components in the mantle, Annu. Rev. Earth Planet. Sci., 11, 371-414, 1983.

Lupton, J. E., D. W. Graham, J. R. Delaney, and H. P. Johnson, Helium isotope variations in Juan de Fuca Ridge basalts, Geophys. Res. Lett., 20, 1851-1854, 1993.

Maclennan, J., D. McKenzie, and K. Gronvold, Plume-driven upwelling under central Iceland, Earth Planet. Sci. Lett., 194, 67-82, 2001.

Mahoney, J. J., J. M. Sinton, M. D. Kurz, J. D. Macdougall, K. J. Spencer, and G. W. Lugmair, Isotope and trace element characteristics of a super-fast spreading ridge: East Pacific Rise, $13-23^{\circ}$ N, Earth Planet. Sci. Lett., 121, 173-193, 1994.

McKenzie, D., The generation and compaction of partially molten rock, J. Petrol., 25, 713-765, 1984.

McKenzie, D., and M. J. Bickle, The volume and composition of melt generated by extension of the lithosphere, J. Petrol., 29, 625-679, 1988.

McKenzie, D., and R. K. O'Nions, Mantle reservoirs and oceanic basalts, Nature, 301, 229-231, 1983.

McKenzie, D., and R. K. O’Nions, Partial melt distribution from inversion of rare earth element concentrations, $J$. Petrol., 32, 1021-1091, 1991.

Menke, W., B. Brandsdóttir, P. Einarsson, and I. T. Bjarnason, Reinterpretation of the RRISP-77 Iceland shear wave profiles, Geophys. J. Int., 126, 166-172, 1996.

Michael, P. J., R. L. Chase, and J. F. Allen, Petrologic and geochemical variations along the southern Explorer ridge, northeast Pacific Ocean, J. Geophys. Res., 94, 13, 89513,918, 1989.

Michael, P. J., et al., Mantle control of a dynamically evolving spreading center: Mid-Atlantic Ridge 31-34 ${ }^{\circ} \mathrm{S}$, Earth Planet. Sci. Lett., 121, 451-468, 1994.

Moore, W. B., G. Schubert, and P. J. Tackley, Three-dimensional simulations of plume-lithosphere interaction at the Hawaiian swell, Science, 279, 1008-1011, 1998.

Moore, W. B., G. Schubert, and P. J. Tackley, The role of rheology in lithospheric thinning by mantle plumes, Geophys. Res. Lett., 26, 1073-1076, 1999.

Moreira, M., and C. Allègre, Rare gas systematics on MidAtlantic Ridge $\left(37-40^{\circ} \mathrm{N}\right)$, Earth Planet. Sci. Lett., 198, 401-416, 2002.

Moreira, M., R. Doucelance, M. D. Kurz, B. Dupré, and C. Allègre, Helium and lead isotope geochemistry of the Azores Archipelago, Earth Planet. Sci. Lett., 169, 489-205, 1999.
Moreira, M., C. Gautheron, K. Breddam, J. Curtice, and M. D. Kurz, Solar neon in the Icelandic mantle: New evidence for an undegassed lower mantle, Earth Planet. Sci. Lett., 185, 15-23, 2001.

Morgan, W. J., Convection plumes in the lower mantle, Nature, 230, 42-43, 1971.

Morgan, W. J., Plate motions and deep mantle convection, Mem. Geol. Soc. Am., 132, 7-22, 1972.

Morgan, W. J., Rodriguez, Darwin, Amsterdam,.., A second type of hotspot island, J. Geophys. Res., 83, 5355-5360, 1978.

Müller, R. D., W. R. Roest, J.-Y. Royer, L. M. Gahagan, and J. G. Slater, A digital age map of the ocean floor, SIO Ref. Ser. 93-30, Scripps Inst. of Oceanogr., La Jolla, Calif., 1993a.

Müller, R. D., J.-Y. Royer, and L. A. Lawver, Revised plate motions relative to the hotspots from combined Atlantic and Indian Ocean hotspot tracks, Geology, 21, 275-278, 1993b.

Müller, R. D., W. R. Roest, and J.-Y. Royer, Asymmetric sea-floor spreading caused by ridge-plume interactions, $\mathrm{Na}$ ture, 396, 455-459, 1998.

Navin, D. A., C. Perice, and M. C. Sinha, The RAMESSES experiment-II. Evidence for accumulated melt beneath a slow spreading ridge from wide-angle refraction and multichannel reflection seismic profiles, Geophys. J. Int., 135, 746-772, 1998.

Nolasco, R., P. Tarits, J. H. Filloux, and A. D. Chave, Magnetotelluric imaging of the Society Islands hotspot, J. Geophys. Res., 103, 30,287-30,309, 1998.

Norton, I. O., Global hotspot reference frames and plate motion, in The History and Dynamics of Global Plate Motion, Geophys. Monogr. Ser., vol. 121, edited by M. A. Richards, R. G. Gordon, and R. D. van der Hilst, pp. 339-357, AGU, Washington, D. C., 2000.

Okal, E. A., and R. Batiza, Hotspots: The first 25 years, in Seamounts, Islands, and Atolls, Geophys. Monogr. Ser., vol. 43, edited by B. H. Keating et al., pp. 1-10, AGU, Washington, D. C., 1987.

Olson, P., Hot spots, swells and mantle plumes, in Magma Transport and Storage, edited by M. P. Ryan, pp. 33-51, John Wiley, Hoboken, N. J., 1990.

Peate, D. W., C. J. Hawkesworth, P. W. van Calsteren, R. N. Taylor, and B. J. Murton, ${ }^{238} \mathrm{U}_{-}{ }^{230} \mathrm{Th}$ constraints on mantle upwelling and plume-ridge interaction along the Reykjanes Ridge, Earth Planet. Sci. Lett., 187, 259-272, 2001.

Phipps Morgan, J., Isotope topology of individual hotspot basalt arrays: Mixing curves or melt extraction trajectories, Geochem. Geophys. Geosyst., 1, Paper number 1999GC000004, 1999.

Phipps Morgan, J., and Y. J. Chen, The genesis of oceanic crust: Magma injection, hydrothermal circulation, and crustal flow, J. Geophys. Res., 98, 6283-6297, 1993.

Plank, T., and C. H. Langmuir, Effects of the melting regime on the composition of the oceanic crust, J. Geophys. Res., 97, 19,749-19,770, 1992.

Ribe, N., The dynamics of plume-ridge interaction: 2. Offridge plumes, J. Geophys. Res., 101, 16,195-16,204, 1996.

Ribe, N., and W. L. Delattre, The dynamics of plume-ridge interaction, 3: The effects of ridge migration, Geophys. J. Int., 133, 511-518, 1998.

Ribe, N., U. R. Christensen, and J. Theissing, The dynamics of plume-ridge interaction, 1: Ridge-centered plumes, Earth Planet. Sci. Lett., 134, 155-168, 1995.

Richards, M. A., and R. W. Griffiths, Thermal entrainment by deflected mantle plumes, Nature, 342, 900-902, 1989.

Saal, A. E., S. R. Hart, N. Shimizu, E. H. Hauri, and G. D. Layne, $\mathrm{Pb}$ isotopic variability in melt inclusions from oceanic island basalt, Polynesia, Science, 282, 1481-1484, 1998. Sandwell, D., and W. H. F. Smith, Marine gravity from Geosat 
and ERS-1 altimetry, J. Geophys. Res., 102, 10,039-10,054, 1997.

Scheirer, D. S., D. W. Forsyth, J. A. Conder, M. A. Eberle, S.-H. Hung, K. T. M. Johnson, and D. W. Graham, Anomalous seafloor spreading of the Southeast Indian Ridge near the Amsterdam-St. Paul Plateau, J. Geophys. Res., 105, 8243-8262, 2000.

Schilling, J.-G., Sea floor evolution: Rare earth evidence, Philos. Trans. R. Soc. London, Ser. A, 268, 663-706, 1971.

Schilling, J.-G., Iceland mantle plume: Geochemical study of Reykjanes Ridge, Nature, 242, 565-571, 1973.

Schilling, J.-G., Upper mantle heterogeneities and dynamics, Nature, 314, 62-67, 1985.

Schilling, J.-G., Fluxes and excess temperatures of mantle plumes inferred from their interaction with migrating midocean ridges, Nature, 352, 397-403, 1991.

Schilling, J.-G., M. B. Bergeron, and R. Evans, Halogens in the mantle beneath the North Atlantic, Philos. Trans. R. Soc. London, Ser. A, 297, 147-178, 1980.

Schilling, J.-G., R. H. Kingsley, and J. D. Devine, Galapagos hot spot-spreading center system: 1 . Spatial petrological and geochemical variations $\left(83^{\circ} \mathrm{W}-101^{\circ} \mathrm{W}\right)$, J. Geophys. Res., 87, 5593-5610, 1982.

Schilling, J.-G., M. Zajac, R. Evans, T. Johnston, W. White, J. D. Devine, and R. Kingsley, Petrologic and geochemical variations along the Mid-Atlantic Ridge from $29^{\circ} \mathrm{N}$ to $73^{\circ} \mathrm{N}$, Am. J. Sci., 283, 510-586, 1983.

Schilling, J.-G., R. Kingsley, D. Fontignie, R. Poreda, and S. Xue, Dispersion of the Jan Mayen and Iceland mantle plumes in the Arctic: A He-Pb-Nd-Sr isotope tracer study of basalts from the Kolbeinsey, Mohns, and Knipovich Ridges, J. Geophys. Res., 104, 10,543-10,569, 1999.

Shaw, P. R., Ridge segmentation, faulting and crustal thickness in the Atlantic Ocean, Nature, 358, 491-493, 1992.

Shaw, W. T., and J. Lin, Models of oceanic ridge lithospheric deformation: Dependence on crustal thickness, spreading rate, and segmentation, J. Geophys. Res., 101, 17,977-17,993, 1996.

Shen, Y., and D. W. Forsyth, Geochemical constraints on initial and final depths of melting beneath mid-ocean ridges, J. Geophys. Res., 100, 2211-2237, 1995.

Shen, Y., S. C. Solomon, I. T. Bjarnason, and C. Wolfe, Seismic evidence for a lower mantle origin of the Iceland plume, Nature, 395, 62-65, 1998.

Sims, K. W. W., D. J. DePaolo, M. T. Murrell, W. S. Baldridge, S. J. Goldstein, and D. A. Clague, Mechanisms of magma generation beneath Hawaii and mid-ocean ridges: Uranium/thorium and samarium/neodymium isotope evidence, Science, 267, 508-512, 1995.

Sinton, C. W., D. M. Christie, and R. A. Duncan, Geochronology of Galápagos seamounts, J. Geophys. Res., 101, 13,689-13,700, 1996.

Sleep, N. H., Lateral flow of hot plume material ponded at sublithospheric depths, J. Geophys. Res., 101, 28,065-28,083, 1996.

Small, C., Observations of ridge-hotspot interactions in the Southern Ocean, J. Geophys. Res., 100, 17,931-17,946, 1995.

Smallwood, J. R., R. S. White, and T. A. Minshull, Sea-floor spreading in the presence of the Iceland plume: The structure of the Reykjanes Ridge at $61^{\circ} 40^{\prime} \mathrm{N}, J$. Geol. Soc. London, 152, 1023-1029, 1995.

Smith, W. H. F., and D. T. Sandwell, Global seafloor topography from satellite altimetry and ship depth soundings, Science, 277, 1957-1962, 1997.

Smoot, N. C., Observations on Gulf of Alaska seamount chains by multibeam sonar, Tectonophysics, 115, 235-246, 1985.

Staples, R. K., R. S. White, B. Branksdóttir, W. Menke, P. K. H. Maguire, and J. H. McBride, Färoe-Iceland ridge experiment: 1. Crustal structure of northeastern Iceland, J.
Geophys. Res., 102, 7849-7866, 1997.

Stein, C. A., and S. Stein, A model for the global variation in oceanic depth and heat flow with lithospheric age, Nature, 359, 123-129, 1992.

Takahashi, E., K. Nakajima, and T. L. Wright, Origin of the Columbia Rivers basalts: Melting model of a heterogeneous plume head, Earth Planet. Sci. Lett., 162, 63-80, 1998.

The MELT Seismic Team, Imaging the deep seismic structure beneath a mid-ocean ridge: The MELT Experiment, Science, 280, 1215-1218, 1998.

Toomey, D. R., E. E. E. Hooft, S. C. Solomon, D. E. James, and M. L. Hall, Upper mantle structure beneath the Galapagos Archipelago from body wave data, Eos Trans. $A G U$, 82(47), Fall Meet. Suppl., Abstract T41D-04, 2001.

Turcotte, D. L., and G. Schubert, Geodynamics, 2nd ed., 456 pp., Cambridge Univ. Press, New York, 2002.

van der Hilst, R., Evidence for deep mantle circulation from global tomography, Nature, 386, 578-584, 1997.

Verma, S. P., and J.-G. Schilling, Galapagos hot spot-spreading center system: $2 .{ }^{87} \mathrm{Sr} /{ }^{86} \mathrm{Sr}$ and large ion lithophile element variations $\left(85^{\circ} \mathrm{W}-101^{\circ} \mathrm{W}\right)$, J. Geophys. Res., 87, 10,83810,856, 1982.

Verma, S. P., J.-G. Schilling, and D. G. Waggoner, Neodymium isotopic evidence for Galapagos hotspot-spreading centre system evolution, Nature, 306, 654-657, 1983.

Vogt, P. R., Asthenosphere motion recorded by the ocean floor south of Iceland, Earth Planet. Sci. Lett., 13, 153-160, 1971.

Vogt, P. R., Evidence for global synchronism in mantle plume convection, and possible significance for geology, Nature, 240, 338-342, 1972.

Vogt, P. R., Plumes, subaxial pipe flow, and topography along the mid-ocean ridge, Earth Planet. Sci. Lett., 29, 309-325, 1976.

Vogt, P. R., Global Magmatic episodes: New evidence and implications for the steady-state mid-oceanic ridge, Geology, 7, 93-98, 1979.

Vogt, P. R., and G. L. Johnson, A longitudinal seismic reflection profile of the Reykjanes ridge: part 1-Evidence for west-flowing bottom water, Earth Planet. Sci. Lett., 18, 4548, 1972.

Weaver, B. L., D. A. Wood, J. Tarney, and J.-L. Joron, Role of subducted sediment in the genesis of ocean island basalts: Geochemical evidence from South Atlantic Ocean islands, Geology, 14, 275-278, 1986.

Weir, N. R. W., R. S. White, B. Brandsdóttir, P. Einarsson, H. Shimamura, H. Shiobara, and the RISE Fieldwork Team, Crustal structure of the northern Reykjanes Ridge and Reykjanes Peninsula, southwest Iceland, J. Geophys. Res, 106, 6347-6368, 2001.

Wessel, P., and L. W. Kroenke, A geometric technique for relocation hotspots and refining absolute plate motions, Nature, 387, 365-369, 1997.

White, N., and B. Lovell, Measuring the pulse of a plume with the sedimentary record, Nature, 387, 888-891, 1997.

White, R., and D. McKenzie, Magmatism at rift zones: The generation of volcanic continental margins and flood basalts, J. Geophys. Res., 94, 7685-7729, 1989.

White, R. S., and D. McKenzie, Mantle plumes and flood basalts, J. Geophys. Res., 100, 17,543-17,585, 1995.

White, R. S., D. McKenzie, and R. K. O’Nions, Oceanic crustal thickness from seismic measurements and rare earth element inversions, J. Geophys. Res., 97, 19,683-19,715, 1992.

White, R. S., J. W. Bown, and J. R. Smallwood, The temperature of the Iceland plume and origin of outward propagating V-shaped ridges, J. Geol. Soc. London, 152, 1039-1045, 1995.

White, W. M., Sources of oceanic basalts: Radiogenic isotopic evidence, Geology, 13, 115-118, 1985. 
Wilson, D. S., and R. N. Hey, History of rift propagation and magnetization intensity for the Cocos-Nazca spreading center, J. Geophys. Res., 100, 10,041-10,056, 1995.

Wilson, J. T., A possible origin of the Hawaiin Islands, Can. J. Phys., 41, 863-870, 1963.

Wolfe, C., I. T. Bjarnason, J. C. VanDecar, and S. C. Solomon, Seismic structure of the Iceland mantle plume, Nature, 385, 245-247, 1997.

Yale, M. M., and J. Phipps Morgan, Asthenosphere flow model of hotspot-ridge interactions: A comparison of Iceland and Kerguelen, Earth Planet. Sci. Lett., 161, 45-56, 1998.

Zhang, Y. S., and R. Tanimoto, Ridges, hotspots and their interaction as observed in seismic velocity maps, Nature, 355, 45-49, 1992.

Zhao, D., Seismic structure and origin of hotspots and mantle plumes, Earth Planet. Sci. Lett., 192, 251-265, 2001.

Zindler, A., and S. Hart, Chemical geodynamics, Annu. Rev. Earth Planet. Sci, 14, 493-571, 1986.

D. Graham, College of Oceanic and Atmospheric Sciences, Oregon State University, Corvallis, OR 97331-5503, USA. (dgraham@coas.oregonstate.edu)

G. Ito, Department of Geology and Geophysics, SOEST, 1680 East-West Road, University of Hawaii, Honolulu, HI 96822, USA. (gito@hawaii.edu)

J. Lin, Department of Geology and Geophysics, Woods Hole Oceanographic Institution, Woods Hole, MA 02543, USA. (jlin@whoi.edu) 